\title{
A fuzzy e-negotiation support system for inter-firm collaborative product development
}

\author{
Faramak Zandi and Madjid Tavana* \\ Business Systems and Analytics Department, La Salle University, Philadelphia, PA 19141, USA
}

(Received 25 April 2011; final version received 19 February 2012)

\begin{abstract}
Significant advances in manufacturing technology and the rapid intensification of the Internet and electronic commerce diffusion have given rise to competitive differentiation and rapid adaptability to competitive change. New product development is a complex and collaborative process that requires negotiation and joint decisionmaking. We propose a fuzzy electronic negotiation (e-negotiation) support system based on cooperative multicriteria game theory. The proposed system comprises three major processes: initialisation, e-negotiation and joint agreement. The Internet is used to facilitate the e-negotiation process and to minimise the response time in the decision-making process. The fuzzy sets are used to overcome issues related to the imprecise or vague judgments and incomplete information in the negotiation process. The proposed system enables the manufacturing parties involved in the negotiation process to determine the optimal coalition form for new product development and choose a common strategy to improve the payoffs of the members of the coalition group. Finally, a case study is used to demonstrate the applicability of the proposed framework and exhibit the efficacy of the procedures and algorithms in the mobile telecommunications industry.
\end{abstract}

Keywords: collaborative product development; multi-criteria decision-making; cooperative multi-criteria game theory; e-negotiation support system; fuzzy sets

\section{Introduction}

The rapid evolution of manufacturing technology and global connectivity has drastically increased organisational awareness and responsiveness to the interactions between the cooperating parties in the manufacturing sector of the economy. Cooperation requires negotiation. Negotiation is a process of social interaction and communication whereby the parties involved in the negotiation process communicate to reach a joint agreement (Thompson and Nadler 2002). The main steps of negotiation are: (1) exchange of information; (2) each party evaluates this information from its own perspective; (3) joint agreement is reached by mutual selection (Thompson 1998). Cooperation has become prevalent in manufacturing, and the possibility to cooperate offers a promising solution for manufacturers to the problem of identifying appropriate trading partners (Choy et al. 2004). Numerous operating modes based on cooperative relations between the manufacturing parties have been widely adopted in practice (Zhao et al. 2010, Renna and Argoneto 2011).

The ability to cooperate and perform negotiation activities over the Internet has greatly increased the ability of the manufacturing partners to reduce costs and shorten cycle times (Chiu et al. 2005). Carmel et al. (1993) have argued that electronic negotiation (e-negotiation) is not only quick and direct but also helps the parties involved in the negotiation process separate the negotiated issues from the personality issues due to the effect of anonymity. The decisionmaking aspect of the negotiation process requires that parties use information to evaluate alternatives and to formulate offers and arguments. The communication aspect of the negotiation process requires parties exchange information to make offers and influence and motivate opposing parties to make counter offers. In spite of the importance of negotiation, achieving higher quality, lower cost and shorter cycle time has been the primary goal of collaborative product development (Noori and Lee 2004, Li et al. 2005, Molina et al. 2005, Ouzizi et al. 2006, Harmancioglu et al. 2007, Pol et al. 2007, Hu et al. 2010). The literature on collaborative product development generally does not effectively support group decisionmaking and negotiation among potential manufacturing partners (Jing and Lu 2010).

In game theory, there are two different approaches to the multilateral cooperation problem, cooperative and non-cooperative approaches (McCain 2008). In other words, the type of solution in game theory largely depends on the behaviour of the decision makers and their relationship. If the decision makers

\footnotetext{
*Corresponding author. Email: tavana@lasalle.edu 
do not cooperate with each other, that is, each of them cares only about its own benefit, then the game is noncooperative. Non-cooperative game theory deals with situations where a decision maker treats the others as competitors. The Nash equilibrium is the most widely used non-cooperative game-theoretic solution (von Neumann and Morgenstern 1944, Nash 1950a). In contrast, if the decision makers are willing to cooperate with each other and to compromise, then the game is cooperative. The cooperative game theory deals with situations in which a group of decision makers work together as collaborators in order to achieve a joint business objective (e.g. to increase total revenue, maximise total profit, increase total market shares, decrease total costs or minimise total costs) (Song and Panayides 2002). In the game theory literature, there are many methods to solve cooperative games. The von Neumann stable set, the core, the kernel, the Shapley value, the nucleolus and the Nash bargaining solution are the most widely used cooperative gametheoretic methods (Nash 1950b, Shapely 1953).

Most of the game theory literature deals with cooperative games in characteristic function form where the characteristic function of a game is a mapping that assigns a precise number, called the worth of the coalition or payoff of the coalition, to each coalition of the players' set. However, the payoff to the coalition in real-world problems is sometimes imprecise or vague. Imprecise payoff may be the result of unquantifiable, incomplete or non-obtainable information. The fuzzy sets theory is ideally suited to handle the ambiguity and impreciseness encountered in game theory (Mares 2000, Wu 2010). When a new product is being developed, it is not normally possible to elicit explicit data because of the implicit nature of early-stage product conceptualisation (Yan et al. 2006). Since Zadeh (1965) introduced fuzzy set theory, and Bellman and Zadeh (1970) described the decision-making method in fuzzy environments, an increasing number of manufacturing studies have dealt with fuzzy-logic-based decisionmaking models for new product development (Büyüközkan and Feyzioğlu 2004, Mikhailov and Tsvetinov 2004, Feyzioğlu and Büyüközkan 2008, Zhang and Chu 2009, Chiang and Che 2010) and cooperative games where the knowledge about the worth of coalitions is described by fuzzy intervals (Nishizaki and Sakawa 2000, Mares 2001, Tsurumi et al. 2001, Espin et al. 2007, Al-Ahmari 2008, Jing and $\mathrm{Lu}$ 2010, Mallozzi et al. 2011). According to Zadeh (1975), it is very difficult for conventional quantification to reasonably express complex situations and it is necessary to use linguistic variables whose values are words or sentences in a natural or artificial language.
New product development is an inter- or intra-firm activity that transforms market opportunities and a set of assumptions about product technology into a product available for sale (Davila 2000, Haque et al. 2000, Krishnan and Ulrich 2001). Schmidt et al. (2001) compared the new product development decisionmaking effectiveness of individuals, face-to-face teams and virtual teams. A virtual team was a geographically and temporally dispersed work group that communicated asynchronously via the Internet. They found that teams made more effective decisions than individuals, and virtual teams made the most effective decisions. Manufacturing alliances are inter-firm cooperative agreements to combine complementary resources between manufacturing firms in an effort to create a more competitive product than either firm could develop independently.

Among the existing technologies to support collaborative product development, the focus has been in sharing product data and providing collaborative tools to bring the multidisciplinary teams together. Huang et al. (2000) proposed a remote web-based decision support system to facilitate the teamwork in a collaborative product development environment where the team members are geographically distributed. Rodriguez and Al-Ashaab (2005) introduced a knowledge-driven decision support system to facilitate knowledge sharing in collaborative product development. Hung et al. (2007) proposed a decision support system for assessing design alternatives for production of modular products in a collaborative product development environment based on the tradeoffs between quality, time and cost. Tseng et al. (2007) studied collaborative product development from technological standpoint and proposed a decision support system that encompassed a marketing information system, a human resources management system, a supply-chain management system, a communication media, an integrated product design studio, a user interface and databases. Li and Qin (2006) summarised the collaborative product development technologies from three aspects: visualisation-based collaborative systems, co-design collaborative systems and concurrent engineering-based collaborative systems. Hu et al. (2010) discussed internet-based intelligent system architecture for collaborative product development built upon service-oriented architecture for handling distributed heterogeneous resource sharing. They proposed a decision support technology to provide efficient and effective knowledge-sharing functionality on demand. Büyüközkan and Arsenyan (2012) present a thorough and comprehensive review of the collaborative product development literature.

The research on optimal coalition formation among manufacturing parties is very limited. Li et al. 
(2005) proposed a partner formation model based on a pre-defined attributes set, called attributes of potential partner. Apart from the basic information such as the name, location, contacts, etc., they considered attributes of a potential partner including the Standard International Trade Classification, the relevant certification situations such as the International Organization for Standardization certifications and the quality assurance measures such as sampling and quality control methods. Yoshimura et al. (2005) argued that the optimal collaboration partners should be selected from a group of candidates, so that production of new products can be achieved at a minimum cost, both financial and in terms of effort and expended resources. Although they acknowledged the importance of financial considerations, their proposed decision support model solely considered technological factors when selecting an optimum collaborative product development partner. Hacklin et al. (2006) showed that optimal coalition assessment approaches in the literature traditionally have aimed at supporting the decision through optimising quantitative measures such as minimised net costs, net rejections and net late deliveries (Kumar et al., 2004). They suggested that the coalition formation decisions must also consider rather soft and qualitative factors such as innovation strength and creativity.

This research is based on the premise that (i) a business process in collaborative product development consists of several decentralised manufacturing partners and (ii) operational decisions of these different partners impact each other's profit. To effectively model and analyse decision-making in such multi-firm situation where the outcome depends on the choice made by every manufacturing partner, game theory is a natural choice. We use cooperative game theory and consider the issue of coalition formation among manufacturing partners in collaborative product development (Nagarajan and Sosic 2008). We also recognise that a central feature of any new product alliances is that they are often marked by two distinct phases of potential contribution: product development and market development. We emphasise the alliance for the product development phase and consider the case in which firms continue to jointly develop a product but compete individually in the market (Amaldoss and Rapoport 2005). The modelling framework in this study differs from the conventional inter-firm collaborative product development studies focusing on technology assessment ( $\mathrm{Li}$ and Qin 2006, Tseng et al. 2007), design alternative selection (Shen et al. 2008, Zhang and Chu 2009), knowledge sharing and knowledge integration considerations (Hung et al. 2008, Chen 2010) or tactical decisions (prices and quantities) (Hung et al. 2007, Yeh et al. 2009).
This study is, in sum, concerned with game-theoretic interactions within new product development alliances whose purpose is to substantially create value through collaborative partner formation strategies. In particular, we develop a set of detailed metrics and a comprehensive framework that unravels the optimal new product development for the collaborating manufacturing partners.

Several studies on negotiation support systems have focused on the quantitative modelling aspects of the negotiation process and showed the usefulness and applicability of the multiple criteria decision-theoretic models in the negotiation process (Munier 1993, Espinasse et al. 1997, Bui et al. 2001, Pekec 2001, Baek and Kim 2007, Kebriaei and Johari Majd 2009). A thorough understanding of the product structure and the tasks to be developed is important in the collaborative product development between manufacturing parties as the products' lifecycles become shorter (Fagerström and Jackson 2002). The traditional product lifecycle management solutions have focused primarily on product design and data management (Trappey and Hsiao 2008). Several systems have been developed to support the collaboration in the early stages of the product lifecycle, like the CyberCO (Huang and Mak 2002), WebBlow (Wang et al. 2003), P_PROCE (Qian and Shenseng 2002) and KdCPD (Rodriguez and Al-Ashaab 2005). Ming et al. (2008) have discussed the need for a new collaborative product development protocol that can promote negotiation and optimal selection of manufacturing partners to speed product development, manage programs effectively and enable strategic sourcing in the early stages of the collaborative product development lifecycle. They argued that this collaboration protocol should include different layers of alignment, such as goal, process, method, message and information.

We propose a fuzzy e-negotiation support system based on cooperative multi-criteria game theory. The proposed system enables the parties involved in the negotiation process to determine the optimal coalition form for new product development and choose a common strategy to improve the payoffs of the members of the coalition group. The Internet is used to facilitate the negotiation process and to minimise the response time in the group decision-making process. The fuzzy sets are used to overcome issues related to the imprecise or vague judgments and incomplete information in the negotiation process. A case study in telecommunication industry is used to exhibit the applicability of the proposed framework. The product lifecycle of the mobile phone in telecommunication industry is shortened and the manufacturing cost is reduced due to stiff competition. 
Most mobile phone manufacturers and integrators have chosen a collaborative product development strategy based on the considerations of cost and delivery time (Chiang and Trappey 2007).

The proposed e-negotiation system offers a potential solution to the organisational problems over the Internet by using asynchronous meetings, which involves working together without being in the same place or at the same time. The technology is used to overcome space and time constraints that burden faceto-face meetings in conventional negotiation. Asynchronous meetings, powered by the Internet increase the range and depth of information access and improve group task performance effectiveness by overcoming process losses (Maruca 2000, Cil et al. 2005, Galin et al. 2007).

As depicted in Figure 1, the proposed e-negotiation support system comprises three processes: initialisation, e-negotiation and joint agreement. The e-negotiation process is embedded in the e-negotiation system bridging the initialisation and joint agreement phases. The system is initialised and the negotiators exchanging their payoff values. The e-negotiation process then determines the optimal coalition form. Next, the negotiators review the outcome and they either reach an agreement or the e-negotiation phase is repeated until all the negotiators involved reach a joint agreement. The Internet provides the basis for the interaction between the parties involved in the enegotiation system. The system utilises a coalitional game to model situations in which negotiators can beneficially form decision-making groups, rather than acting individually. Additionally, an outcome of a coalitional game could consist of a partition of the set of negotiators into groups, together with an action for each group in the partition.

This article is organised into five sections. The next section presents the mathematical notations and definitions used in our model. In section 3, we illustrate the details of the proposed framework. In section 4 , we present a case study to demonstrate the applicability of the proposed framework and exhibit the efficacy of the procedures and algorithms in the mobile telecommunications industry. In section 5, we conclude with our conclusions and future research directions.

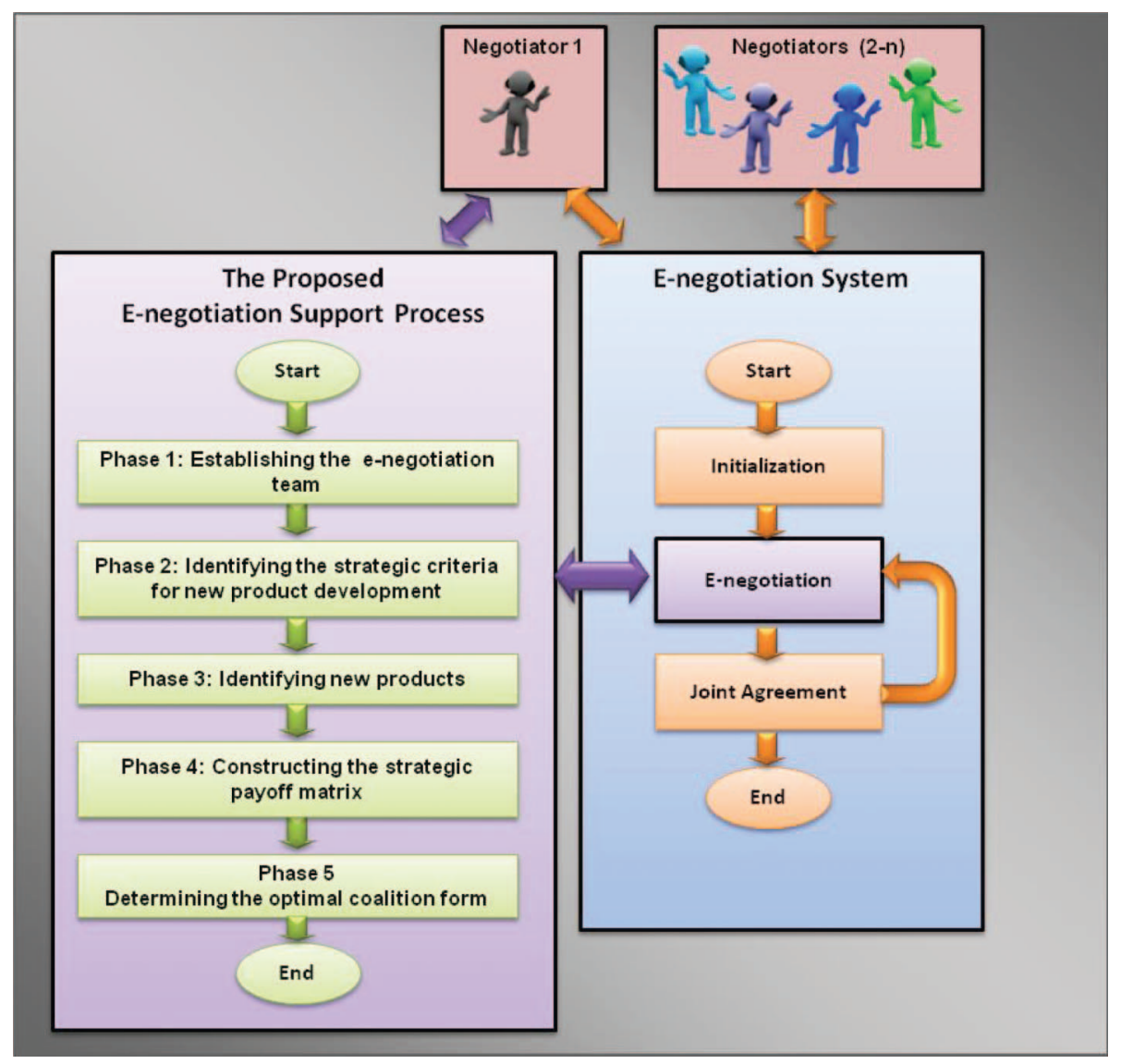

Figure 1. The proposed e-negotiation support system. 


\section{The mathematical notations}

Let us introduce the following mathematical notations and definitions used throughout this article:

\begin{tabular}{|c|c|}
\hline$m$ & The number of new products \\
\hline$n$ & The number of e-negotiation team members \\
\hline $\operatorname{vot}(A)$ & $\begin{array}{l}\text { The voting power of the enterprise in the e- } \\
\text { negotiation team member } T(e-\text { negotiation })\end{array}$ \\
\hline $\operatorname{vot}\left(y_{j}\right)$ & $\begin{array}{l}\text { The voting power of the e-negotiation team } \\
\text { member } T(e-\text { negotiation })\end{array}$ \\
\hline$N$ & The set of the e-negotiation team \\
\hline$S$ & $\begin{array}{l}\text { A coalition that defines a subset of the } \\
\text { e-negotiation team as one negotiator }\end{array}$ \\
\hline $\bar{S}$ & $\begin{array}{l}\text { A complementary coalition of } \\
\quad S(\bar{S}=N-S)\end{array}$ \\
\hline$v_{h}(A)$ & $\begin{array}{l}\text { The value of the company's characteristic } \\
\text { function of the } h \text { th criterion }\end{array}$ \\
\hline$v_{h}\left(y_{j}\right)$ & $\begin{array}{l}\text { The value of the } j \text { th negotiator's characteristic } \\
\text { function of the } h \text { th criterion }\end{array}$ \\
\hline$v_{h}^{\prime}(A)$ & $\begin{array}{l}\text { The normalised value of the company's } \\
\text { characteristic function of the } h \text { th criterion }\end{array}$ \\
\hline$v_{h}^{\prime}\left(y_{j}\right)$ & $\begin{array}{l}\text { The normalised value of the } j \text { th negotiator's } \\
\text { characteristic function of the } h \text { th criterion }\end{array}$ \\
\hline$I(A)$ & $\begin{array}{l}\text { The value of the company's imputation } \\
\text { evaluated }\end{array}$ \\
\hline$I\left(y_{j}\right)$ & The value of the $j$ th negotiator's imputation \\
\hline$\tilde{u}_{h}(A(i))$ & $\begin{array}{l}\text { The fuzzy weighted collective value of the } \\
\text { payoff of the } h \text { th criterion evaluated by the } \\
\text { enterprise for the } i \text { th new product }\end{array}$ \\
\hline$\tilde{u}_{h}\left(y_{j}(i)\right)$ & $\begin{array}{l}\text { The fuzzy weighted collective value of the } \\
\text { payoff of the } h \text { th criterion evaluated by the } \\
\text { th e-negotiation team member for the } i \text { th } \\
\text { new product }\end{array}$ \\
\hline$\tilde{u}_{h}^{k}(A(i))$ & $\begin{array}{l}\text { The individual fuzzy value of the payoff of the } \\
h \text { th criterion evaluated by the enterprise for } \\
\text { the } i \text { th new product }\end{array}$ \\
\hline$\tilde{u}_{h}^{k}\left(y_{j}(i)\right)$ & $\begin{array}{l}\text { The individual fuzzy value of the payoff of the } \\
h \text { th criterion evaluated by the } j \text { th } \\
\text { e-negotiation team member for the } i \text { th new } \\
\text { product }\end{array}$ \\
\hline
\end{tabular}

\section{The proposed framework}

The modular model depicted in Figure 2 is proposed to determine the optimal coalition form:

This proposed framework in embedded in the e-negotiation system described earlier. Figure 3 shows the interface between the local process and the webbased process in the proposed e-negotiation system. The local process is initiated by the negotiator using the local interface and establishing an e-negotiation team for the new product development. Next, the negotiators use the web-based interface to identify the strategic criteria for the new product development, identify new products and construct the strategic payoff matrix. The optimal coalition form is then determined using the local process. Finally, the coalition form obtained in the local process is used to support the negotiators in reaching a joint agreement.

\subsection{Phase 1: establishing the e-negotiation team}

In this phase, we establish the e-negotiation team as follows:

$$
T(e-\text { negotiation })=\left(A, y_{1}, \ldots, y_{n}\right)
$$

Next, we determine a voting power weight to each member of the e-negotiation team as follows:

$$
\operatorname{VOT}=\left(\operatorname{vot}(A), \operatorname{vot}\left(y_{1}\right), \ldots, \operatorname{vot}\left(y_{n}\right)\right)
$$

\subsection{Phase 2: identifying the strategic criteria for new product development}

In this phase, the e-negotiation team determines a list of the strategic criteria relevant to the new product development. Let us consider $c_{1}, c_{2}, \ldots, c_{p}$ as the strategic criteria.

\subsection{Phase 3: identifying new products}

In this phase, the e-negotiation team determines a list of new products. Let us assume that they have identified $m$ new products as follows:

$$
N(P)=\left[n\left(p_{1}\right), n\left(p_{2}\right), \ldots, n\left(p_{m}\right)\right]
$$

\subsection{Phase 4: constructing the strategic payoff matrix}

In this phase, the cooperative game theory approach is used to construct a strategic payoffs matrix for each strategic e-negotiation. This phase is divided into the following two steps.

\subsubsection{Step 4-1: calculating the individual fuzzy payoff matrix}

In this step, the individual fuzzy expected payoffs of each new product are evaluated by the e-negotiation team member $T(e-n e g o t i a t i o n)$ using the matrix shown in Table 1.

The following trapezoidal fuzzy numbers are used to find the individual fuzzy present values of the expected payoffs for each e-negotiation evaluated by the e-negotiation team member $T(e-n e g o t i a t i o n)$ :

$$
\begin{aligned}
\tilde{u}_{h}^{k}(A(i))= & \left(\left(u_{h}^{k}(A(i))\right)^{c},\left(u_{h}^{k}(A(i))\right)^{d},\right. \\
& \left.\left(u_{h}^{k}(A(i))\right)^{\alpha},\left(u_{h}^{k}(A(i))\right)^{\beta}\right) \\
\tilde{u}_{h}^{k}\left(y_{j}(i)\right)= & \left(\left(u_{h}^{k}\left(y_{j}(i)\right)\right)^{c},\left(u_{h}^{k}\left(y_{j}(i)\right)\right)^{d},\right. \\
& \left.\left(u_{h}^{k}\left(y_{j}(i)\right)\right)^{\alpha},\left(u_{h}^{k}\left(y_{j}(i)\right)\right)^{\beta}\right)
\end{aligned}
$$




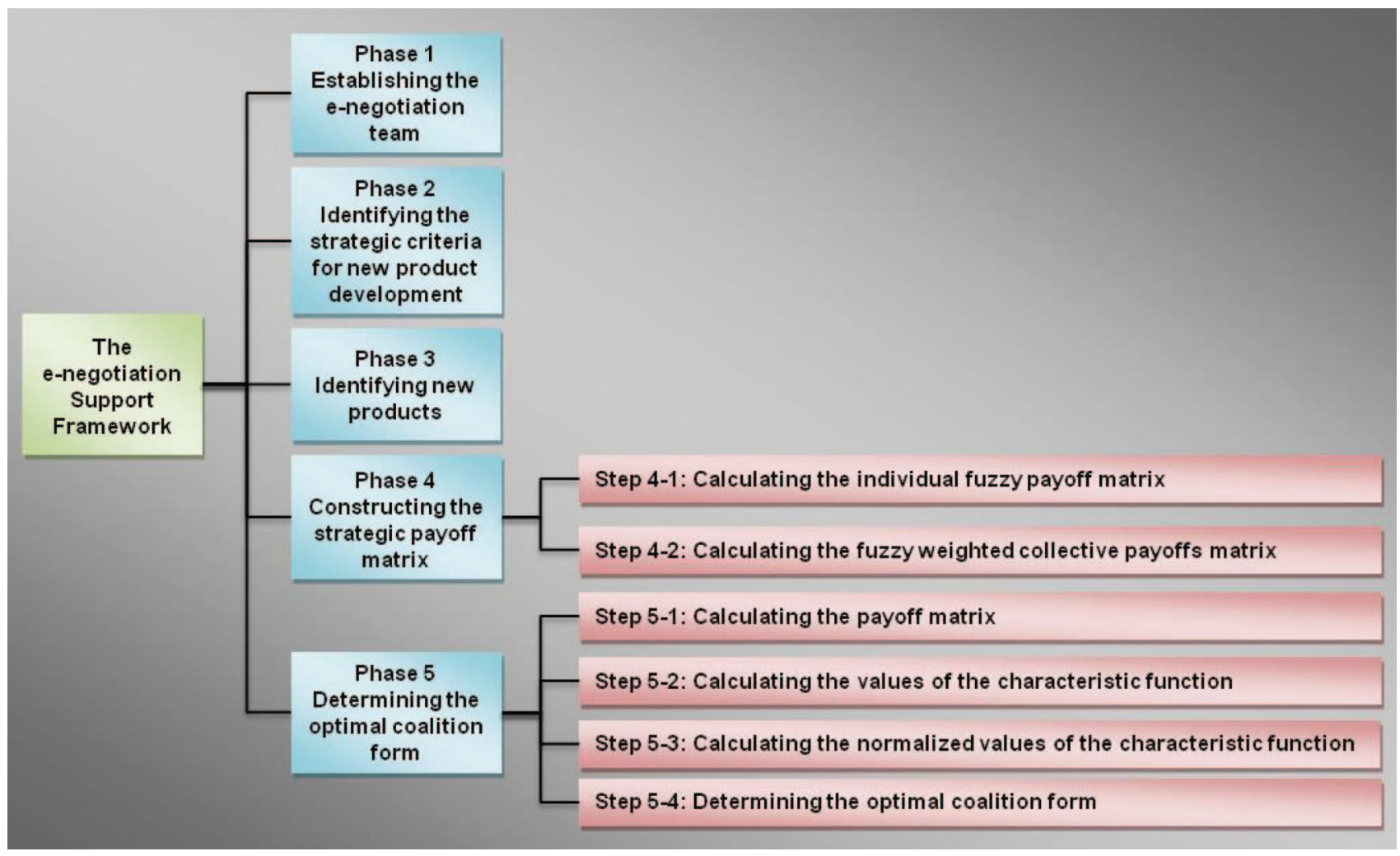

Figure 2. The proposed e-negotiation support framework.

\subsubsection{Step 4-2: calculating the fuzzy weighted collective payoffs matrix}

With regard to step 4-1, the individual fuzzy present value of the expected payoffs for each e-negotiation is aggregated using the voting powers to form a fuzzy weighted collective expected payoffs matrix as shown in Table 2.

$$
\begin{aligned}
\tilde{u}_{h}(A(i))= & \left(\left(u_{h}(A(i))\right)^{c},\left(u_{h}(A(i))\right)^{d},\right. \\
& \left.\left(u_{h}(A(i))\right)^{\alpha},\left(u_{h}(A(i))\right)^{\beta}\right) \\
\tilde{u}_{h}\left(y_{j}(i)\right)= & \left(\left(u_{h}\left(y_{j}(i)\right)\right)^{c},\left(u_{h}\left(y_{j}(i)\right)\right)^{d},\right. \\
& \left.\left(u_{h}\left(y_{j}(i)\right)\right)^{\alpha},\left(u_{h}\left(y_{j}(i)\right)\right)^{\beta}\right) \\
{\left[\tilde{u}_{h}(A(i))\right]=} & \frac{\sum_{k=1}^{n}(\operatorname{vot}(k))\left(\left[\tilde{u}_{h}^{k}(A(i))\right]\right)}{\sum_{k=1}^{n} \operatorname{vot}(k)} ; \\
h= & 1,2, \ldots, p ; i=1,2, \ldots, m . \\
{\left[\tilde{u}_{h}\left(y_{j}(i)\right)\right]=} & \sum_{k=1}^{n}(\operatorname{vot}(k))\left(\left[\tilde{u}_{h}^{k}\left(y_{j}(i)\right)\right]\right) \\
\sum_{k=1}^{n} \operatorname{vot}(k) & 1,2, \ldots, p ; i=1,2, \ldots, m
\end{aligned}
$$

\subsection{Phase 5: Determining the optimal coalition form}

This phase is divided into the following four steps:

\subsubsection{Step 5-1: calculating the payoff matrix}

In this step, all coalitions are identified. Then, the payoff matrices are depicted in coalitional form as shown in Tables 3-6.

\subsubsection{Step 5-2: calculating the values of the characteristic function}

In this step, the values of the characteristic functions are calculated for all coalitions using the following models:

$\operatorname{Max} v_{h}(A)$

Subject to (Strategic Game Model $F_{1}$ ):

$$
\begin{aligned}
& \sum_{r} p_{r} \cdot \tilde{u}_{h}\left(s=\{A(i)\}, \bar{s}=\left\{y_{1}(r), y_{2}(r), \ldots, y_{n}(r)\right\}\right) \\
& \quad \geq v_{h}(A) ; i=1,2, \ldots, m ; h=1,2, \ldots, p \\
& \sum_{r} p_{r}=1
\end{aligned}
$$

$p_{r} \geq 0, v_{h}(A):$ Free variable 


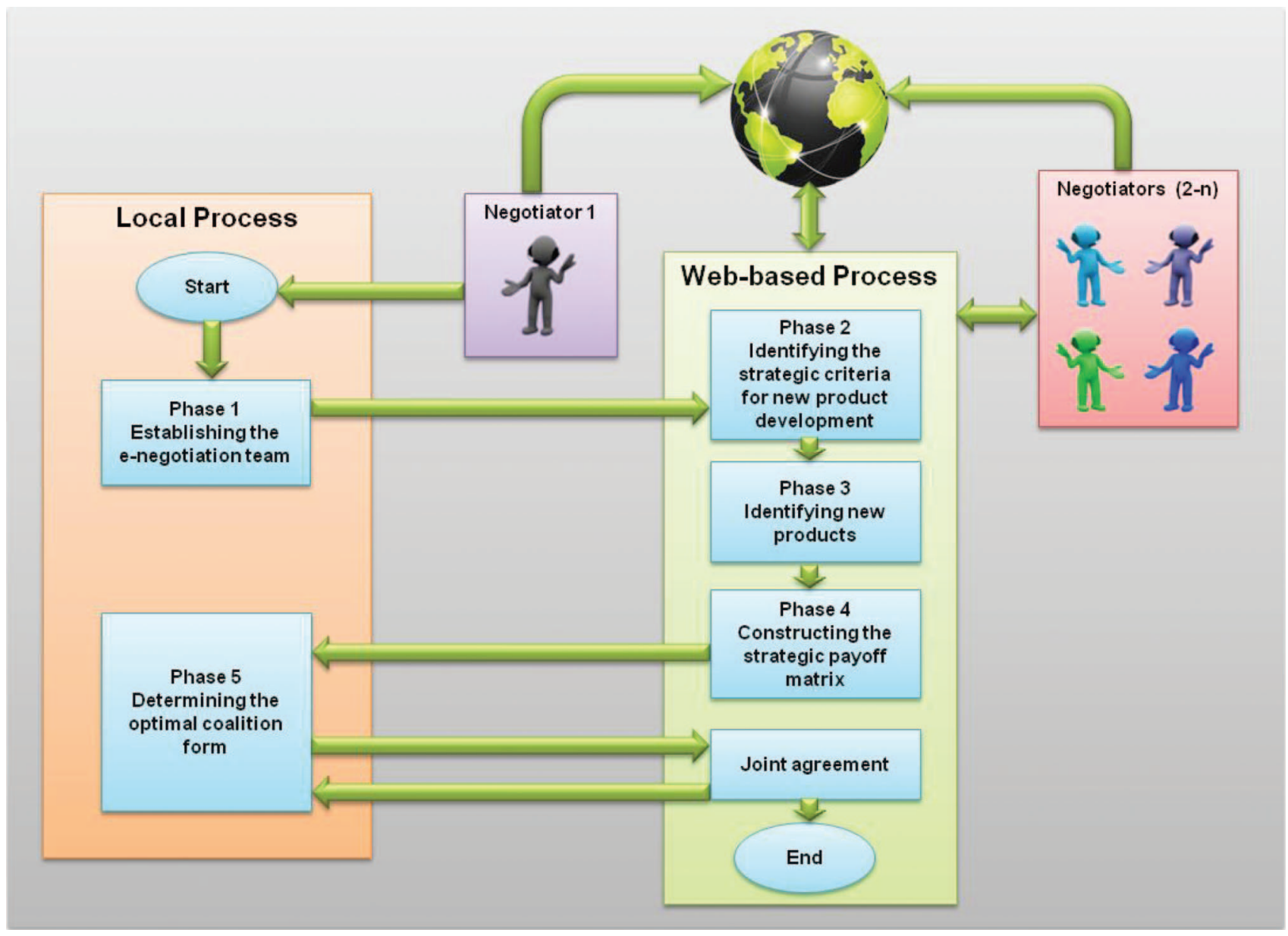

Figure 3. The interface between the local processes and the web-based processes.

Table 1. The fuzzy individual payoffs matrix for the ith member of the e-negotiation team.

\begin{tabular}{|c|c|c|c|c|c|c|c|c|c|}
\hline \multirow[b]{3}{*}{ Strategy combinations } & \multicolumn{9}{|c|}{ Criteria } \\
\hline & \multicolumn{4}{|c|}{$c_{1}$} & \multirow{2}{*}{$\begin{array}{l}\cdots \\
\cdots \\
\end{array}$} & \multicolumn{4}{|c|}{$c_{p}$} \\
\hline & $A$ & $y_{1}$ & $\cdots$ & $y_{n}$ & & $A$ & $y_{1}$ & $\cdots$ & $y_{n}$ \\
\hline$\left(A(1), y_{1}(1), \ldots, y_{n}(1)\right)$ & $\tilde{u}_{1}^{k}(A(1))$ & $\tilde{u}_{1}^{k}\left(y_{1}(1)\right)$ & $\cdots$ & $\tilde{u}_{1}^{k}\left(y_{n}(1)\right)$ & $\cdots$ & $\tilde{u}_{p}^{k}(A(1))$ & $\tilde{u}_{p}^{k}\left(y_{1}(1)\right)$ & $\cdots$ & $\tilde{u}_{p}^{k}\left(y_{n}(1)\right)$ \\
\hline$\left(A(m), y_{1}(m), \ldots, y_{n}(m)\right)$ & $\begin{array}{c}\vdots \\
\tilde{u}_{1}^{k}(A(m))\end{array}$ & $\begin{array}{c}\vdots \\
\tilde{u}_{1}^{k}\left(y_{1}(m)\right)\end{array}$ & $\begin{array}{c}\vdots \\
\cdots\end{array}$ & $\begin{array}{c}\vdots \\
\tilde{u}_{1}^{k}\left(y_{n}(m)\right)\end{array}$ & $\cdots$ & $\begin{array}{c}\vdots \\
\tilde{u}_{p}^{k}(A(m))\end{array}$ & $\begin{array}{c}\vdots \\
\tilde{u}_{p}^{k}\left(y_{1}(m)\right)\end{array}$ & $\begin{array}{c}\vdots \\
\cdots\end{array}$ & $\begin{array}{c}\vdots \\
\tilde{u}_{p}^{k}\left(y_{n}(m)\right)\end{array}$ \\
\hline
\end{tabular}

Table 2. The fuzzy weighted collective payoffs matrix of the e-negotiation team.

\begin{tabular}{|c|c|c|c|c|c|c|c|c|c|}
\hline \multirow[b]{3}{*}{ Strategy combinations } & \multicolumn{9}{|c|}{ Criteria } \\
\hline & \multicolumn{4}{|c|}{$c_{1}$} & \multirow{2}{*}{$\begin{array}{l}\cdots \\
\cdots\end{array}$} & \multicolumn{4}{|c|}{$c_{p}$} \\
\hline & $A$ & $y_{1}$ & $\ldots$ & $y_{n}$ & & $A$ & $y_{1}$ & $\ldots$ & $y_{n}$ \\
\hline$\left(A(1), y_{1}(1), \ldots, y_{n}(1)\right)$ & $\tilde{u}_{1}(A(1))$ & $\tilde{u}_{1}\left(y_{1}(1)\right)$ & $\cdots$ & $\tilde{u}_{1}\left(y_{n}(1)\right)$ & $\cdots$ & $\tilde{u}_{p}(A(1))$ & $\tilde{u}_{p}\left(y_{1}(1)\right)$ & $\cdots$ & $\tilde{u}_{p}\left(y_{n}(1)\right)$ \\
\hline $\begin{array}{l}\vdots \\
\left(A(m), y_{1}(m), \ldots, y_{n}(m)\right)\end{array}$ & $\begin{array}{c}\vdots \\
\tilde{u}_{1}(A(m))\end{array}$ & $\begin{array}{c}\vdots \\
\tilde{u}_{1}\left(y_{1}(m)\right)\end{array}$ & $\begin{array}{c}\vdots \\
\cdots\end{array}$ & $\begin{array}{c}\vdots \\
\tilde{u}_{1}\left(y_{n}(m)\right)\end{array}$ & $\begin{array}{l}\cdots \\
\cdots\end{array}$ & $\begin{array}{c}\vdots \\
\tilde{u}_{p}(A(m))\end{array}$ & $\begin{array}{c}\vdots \\
\tilde{u}_{p}\left(y_{1}(m)\right)\end{array}$ & $\begin{array}{c}\vdots \\
\cdots\end{array}$ & $\begin{array}{c}\vdots \\
\tilde{u}_{p}\left(y_{n}(m)\right)\end{array}$ \\
\hline
\end{tabular}



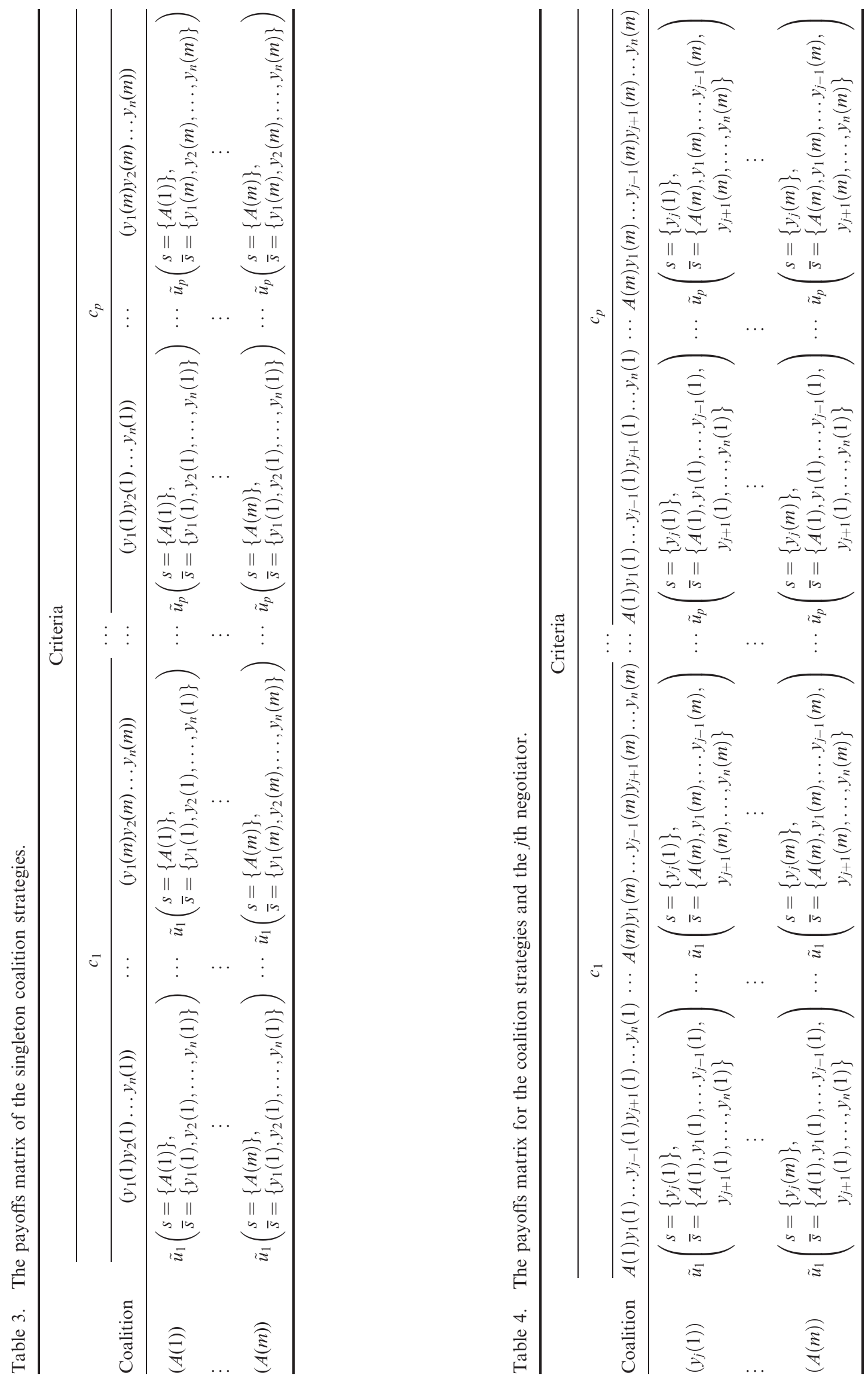
International Journal of Computer Integrated Manufacturing

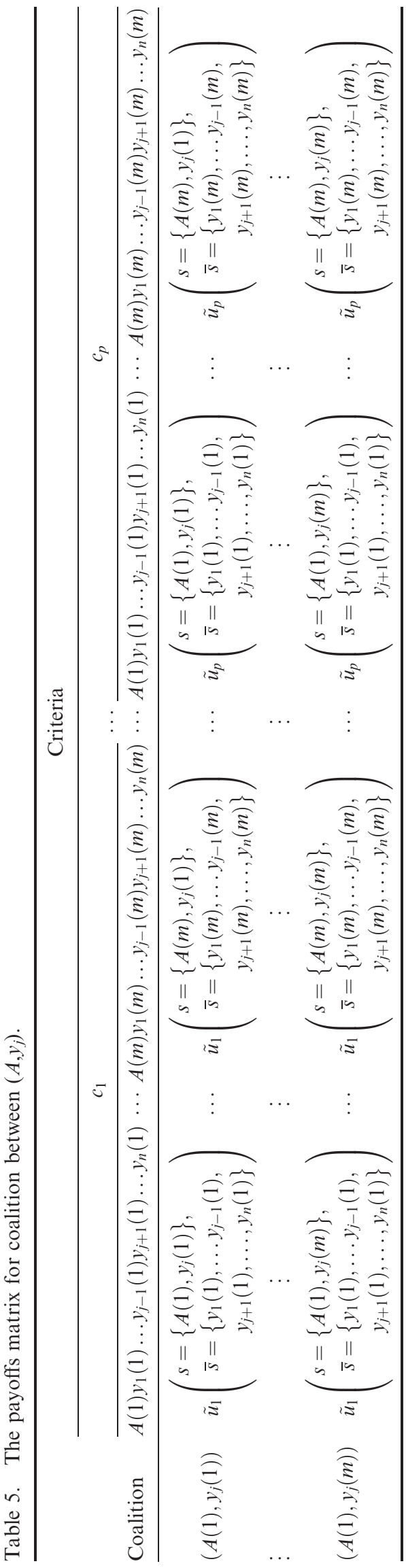

and

$\operatorname{Max} v_{h}\left(y_{j}\right)$

Subject to (Strategic Game Model $F_{2}$ ) :

$\sum_{r} p_{r} . \tilde{u}_{h}\left(s=\left\{y_{j}(i)\right\}, \bar{s}=\left\{A(r), y_{1}(r), \ldots, y_{j-1}(r)\right.\right.$,

$\left.\left.y_{j+1}(r), \ldots, y_{n}(r)\right\}\right) \geq v_{h}\left(y_{j}\right) ; i=1,2, \ldots, m ;$

$h=1,2, \ldots, p$

$\sum_{r} p_{r}=1$

$p_{r} \geq 0, v_{h}\left(y_{j}\right):$ Free variable.

and

$\operatorname{Max} v_{h}\left(A, y_{j}\right)$

Subject to (Strategic Game Model $F_{3}$ ):

$\sum_{r} p_{r} \cdot \tilde{u}_{h}\left(s=\left\{A(i), y_{j}\left(i^{\prime}\right)\right\}, \bar{s}=\left\{y_{1}(r), \ldots, y_{j-1}(r)\right.\right.$,

$\left.\left.y_{j+1}(r), \ldots, y_{n}(r)\right\}\right) \geq v_{h}\left(A, y_{j}\right) ; i, i^{\prime}=1,2, \ldots, m ;$

$h=1,2, \ldots, p$

$\sum_{r} p_{r}=1$

$p_{r} \geq 0, v_{h}\left(A, y_{j}\right):$ Free variable

and

$\operatorname{Max} v_{h}\left(A, y_{1}, \ldots, y_{n}\right)$

Subject to (Strategic Game Model $F_{q}$ )

$\sum_{r} p_{r} \cdot \tilde{u}_{h}\left(s=\left\{A(r), y_{1}(r), \ldots, y_{n}(r)\right\}\right)$

$\geq v_{h}\left(A, y_{1}, \ldots, y_{n}\right) ; i=1,2, \ldots, m ; h=1,2, \ldots, p$

$\sum_{r} p_{r}=1$

$p_{r} \geq 0, v_{h}\left(A, y_{1}, \ldots, y_{n}\right):$ Free variable

The optimal solutions for these models form the values of the characteristic functions as shown in Table 7.

3.5.3. Step 5-3: calculating the normalised values of the characteristic function

In this step, the normalised values of the characteristic function are calculated for all coalitions as shown in Table 8 .

$$
v_{h}^{\prime}(a)=\frac{v_{h}(a)-\sum_{i \in a} v_{h}(i)}{v_{h}(N)-\sum_{i \in N} v_{h}(i)}
$$


Table 6. The payoffs matrix of the grand coalition.

\begin{tabular}{lccc}
\hline & \multicolumn{3}{c}{ Criteria } \\
\cline { 2 - 4 } Coalition & $c_{1}$ & $\cdots$ & $c_{p}$ \\
\hline$A(1) y_{1}(1) \ldots y_{n}(1)$ & $\tilde{u}_{1}\left(s=\left\{A(1), y_{1}(1), \ldots, y_{n}(1)\right\}\right)$ & $\ldots$ & $\tilde{u}_{p}\left(s=\left\{A(1), y_{1}(1), \ldots, y_{n}(1)\right\}\right)$ \\
$\vdots$ & $\vdots$ & $\cdots$ & $\vdots$ \\
$A(m) y_{1}(m) \ldots y_{n}(m)$ & $\tilde{u}_{1}\left(s=\left\{A(m), y_{1}(m), \ldots, y_{n}(m)\right\}\right)$ & $\ldots$ & $\tilde{u}_{p}\left(s=\left\{A(m), y_{1}(m), \ldots, y_{n}(m)\right\}\right)$ \\
\hline
\end{tabular}

Table 7. The values of the characteristic functions.

\begin{tabular}{|c|c|c|c|c|c|c|c|c|}
\hline \multicolumn{9}{|c|}{ Criteria } \\
\hline \multicolumn{4}{|c|}{$c_{1}$} & & \multicolumn{4}{|c|}{$c_{p}$} \\
\hline Singleton coalitions & 2-coalitions & $\ldots$ & Grand coalition & $\ldots$ & Singleton coalitions & 2-coalitions & $\ldots$ & Grand coalition \\
\hline$v_{1}(A)$ & $v_{1}\left(A, y_{1}\right)$ & $\ldots$ & $v_{1}\left(A, y_{1}, \ldots, y_{n}\right)$ & $\ldots$ & $v_{p}(A)$ & $v_{p}\left(A, y_{1}\right)$ & $\cdots$ & $v_{p}\left(A, y_{1}, \ldots, y_{n}\right)$ \\
\hline$\vdots$ & $\vdots$ & $\vdots$ & $\vdots$ & $\cdots$ & $\vdots$ & $\vdots$ & $\vdots$ & $\vdots$ \\
\hline$v_{1}\left(y_{n}\right)$ & $v_{1}\left(y_{n-1}, y_{n}\right)$ & $\cdots$ & - & $\ldots$ & $v_{p}\left(y_{n}\right)$ & $v_{p}\left(y_{n-1}, y_{n}\right)$ & $\ldots$ & - \\
\hline
\end{tabular}

Table 8 . The normalised values of the characteristic functions.

\begin{tabular}{|c|c|c|c|c|c|c|c|c|}
\hline \multicolumn{9}{|c|}{ Criteria } \\
\hline \multicolumn{4}{|c|}{$c_{1}$} & & \multicolumn{4}{|c|}{$c_{p}$} \\
\hline Singleton coalitions & 2-coalitions & $\ldots$ & Grand coalition & $\ldots$ & Singleton coalitions & 2-coalitions & $\ldots$ & Grand coalition \\
\hline$v_{1}^{\prime}(A)$ & $v_{1}^{\prime}\left(A, y_{1}\right)$ & $\cdots$ & $v_{1}^{\prime}\left(A, y_{1}, \ldots, y_{n}\right)$ & $\cdots$ & $v_{p}^{\prime}(A)$ & $v_{p}^{\prime}\left(A, y_{1}\right)$ & $\ldots$ & $v_{p}^{\prime}\left(A, y_{1}, \ldots, y_{n}\right)$ \\
\hline$\vdots$ & $\vdots$ & $\vdots$ & $\vdots$ & $\cdots$ & $\vdots$ & $\vdots$ & $\vdots$ & $\vdots$ \\
\hline$v_{1}^{\prime}\left(y_{n}\right)$ & $v_{1}^{\prime}\left(y_{n-1}, y_{n}\right)$ & $\ldots$ & - & $\ldots$ & $v_{p}^{\prime}\left(y_{n}\right)$ & $v_{p}^{\prime}\left(y_{n-1}, y_{n}\right)$ & $\ldots$ & - \\
\hline
\end{tabular}

\subsubsection{Step 5-4: determining the optimal coalition form}

In this step, the optimal coalition form is determined using the model $\mathrm{G}$ given below:

$\operatorname{Max} \phi$

Subject to (ModelG) :

$\varphi \leq I(A)+I\left(y_{1}\right)-\operatorname{Min}\left\{v_{1}^{\prime}\left(A, y_{1}\right), \ldots, v_{p}^{\prime}\left(A, y_{1}\right)\right\}$
$\varphi \leq I(A)+I\left(y_{2}\right)-\operatorname{Min}\left\{v_{1}^{\prime}\left(A, y_{2}\right), \ldots, v_{p}^{\prime}\left(A, y_{2}\right)\right\}$

$I(A)+I\left(y_{1}\right)+\cdots+I\left(y_{n}\right)=1$

$I(A), I\left(y_{1}\right), \ldots, I\left(y_{n}\right) \geq 0$

$\phi$ : Free variable

The optimal solution for model $(\mathrm{G}), I^{*}(A)$, $I^{*}\left(y_{1}\right), \ldots, I^{*}\left(y_{n}\right)$, represents the optimal values of the imputations and points of the core. Finally, ranked values $I^{*}\left(y_{1}\right), \ldots, I^{*}\left(y_{n}\right)$ represent the optimal coalition form for the new product development.

In the next section, we present a case study to demonstrate the applicability of the proposed framework and exhibit the efficacy of the procedures and algorithms in the mobile telecommunications industry.

\section{Case study}

The mobile telecommunications business, driven by innovative technologies and globalisation, is undergoing a critical revolution. Recent advances in technology and globalisation are changing business functions and practices. Cellular technology generations, from Global System for Mobile Communication (GSM) to 3G Universal Mobile Telecommunication Systems (UMTS) and 4G Worldwide Interoperability for Microwave Access (WiMax), are continuously 
enhancing the qualities and capabilities of mobile services and providing new opportunities for telecommunication industry. The Appllet company ${ }^{1}$ is an American multinational corporation that designs and markets consumer electronics. The company is planning to launch a new line of mobile phones called iTel. ${ }^{2}$ While Appllet had extensive experience in the design and development of mobile phones, they lacked semiconductor experience and needed to form a coalition with a semiconductor company to produce the new iTel mobile phones. The management at Appllet agreed to use the proposed e-negotiation support system in this study to determine an optimal coalition form for their new product development.

\subsection{Phase 1: establishing the e-negotiation team}

In this phase, we established an e-negotiation team as follows:

$$
T(e-\text { negotiation })=\left(A, y_{1}, y_{2}\right)
$$

Next, we determined a voting power weight to each member of the e-negotiation team as follows:

$$
V=\left(v(A), v\left(y_{1}\right), v\left(y_{2}\right)\right)
$$

\subsection{Phase 2: identifying the strategic criteria for new product development}

In this phase, the e-negotiation team determined the following five strategic criteria (Porter 1980, 7-33) relevant to the new product development:

- $c_{1}$ : Threat of entry - New players to a market most likely bring in new capacity and additional resources. As a result, the prices might drop and the costs for the existing players might increase.

- $c_{2}$ : Intensity of rivalry among existing players The existing players most likely compete using tactics like price competition, advertising and enhanced customer service.

- $c_{3}$ : Pressure from substitute products - The mobile telecommunications industry is also competing in a sense with substitute products. Substitute products most likely limit the prices by setting a ceiling.

- $c_{4}$ : Bargaining power of buyers - The buyers' goal is to negotiate the prices down and quality up. This most likely results in a competition among the players in the market.

- $c_{5}$ : Bargaining power of suppliers - The suppliers usually try to squeeze higher price for products with lesser quality.

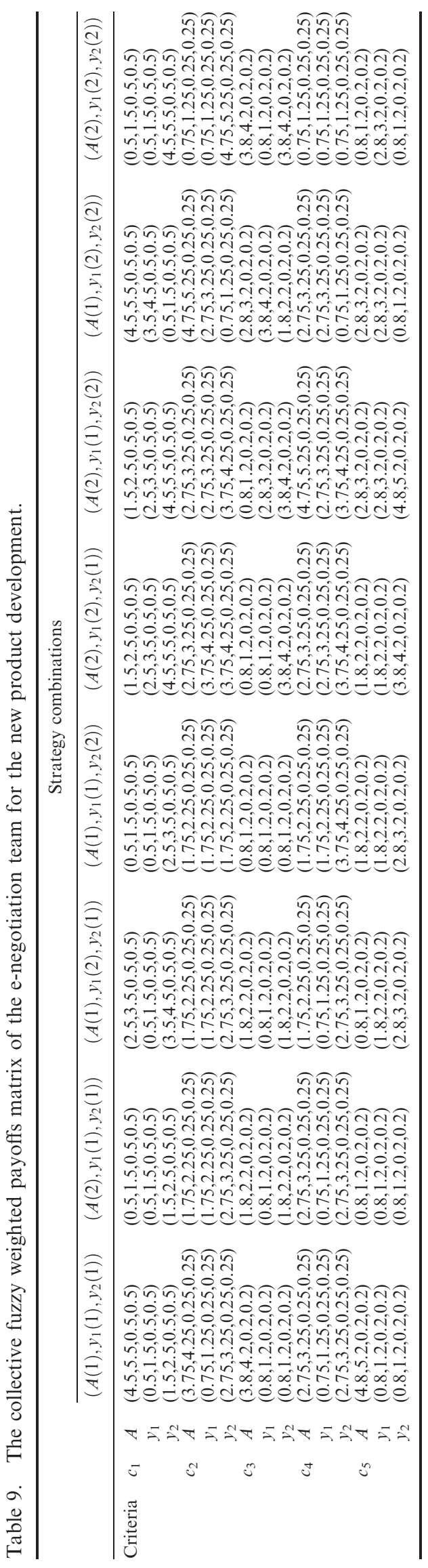




\subsection{Phase 3: identifying new products}

In phase 3 , the e-negotiation team was advised by the management team to consider the following two new iTel products:

$$
N(P)=\left[n\left(p_{1}\right), n\left(p_{2}\right)\right]=\left[5 G_{1}, 5 G_{2}\right]
$$

\subsection{Phase 4: constructing the strategic payoff matrix}

In step 4-1, the e-negotiation team used Equations (4) and (5) to determine an individual fuzzy expected payoffs matrix for each of the two new products evaluated by each e-negotiation team member. In step 4-2, the e-negotiation team used Equations (6) and (9) to determine the individual fuzzy present value of the expected payoffs. Next, the individual fuzzy present value of the expected payoffs was aggregated by the voting powers to form a collective fuzzy weighted expected payoffs matrix as shown in Table 9.

\subsection{Phase 5: determining the optimal coalition form}

In step 5-1, all coalitions were identified and the payoff matrices were depicted in coalitional form as shown in Tables 10-16.

In step 5-2, the values of the characteristic functions were calculated for all coalitions using the following models:

Table 10. The payoffs matrix of the singleton coalition strategies for Appllet.

\begin{tabular}{|c|c|c|c|}
\hline \multirow[b]{2}{*}{ Criteria } & \multirow{2}{*}{$\begin{array}{c}\text { Strategy } \\
\text { combinations }\end{array}$} & \multicolumn{2}{|c|}{ The singleton coalition } \\
\hline & & $A(1)$ & $A(2)$ \\
\hline \multirow[t]{4}{*}{$c_{1}$} & $y_{1}(1), y_{2}(1)$ & $(4.5,5.5,0.5,0.5)$ & $(0.5,1.5,0.5,0.5)$ \\
\hline & $y_{1}(2), y_{2}(1)$ & $(2.5,3.5,0.5,0.5)$ & $(1.5,2.5,0.5,0.5)$ \\
\hline & $y_{1}(1), y_{2}(2)$ & $(0.5,1.5,0.5,0.5)$ & $(1.5,2.5,0.5,0.5)$ \\
\hline & $y_{1}(2), y_{2}(2)$ & $(4.5,5.5,0.5,0.5)$ & $(0.5,1.5,0.5,0.5)$ \\
\hline \multirow[t]{4}{*}{$c_{2}$} & $y_{1}(1), y_{2}(1)$ & $(3.75,4.25,0.25,0.25)$ & $(1.75,2.25,0.25,0.25)$ \\
\hline & $y_{1}(2), y_{2}(1)$ & $(1.75,2.25,0.25,0.25)$ & $(2.75,3.25,0.25,0.25)$ \\
\hline & $y_{1}(1), y_{2}(2)$ & $(1.75,2.25,0.25,0.25)$ & $(2.75,3.25,0.25,0.25)$ \\
\hline & $y_{1}(2), y_{2}(2)$ & $(4.75,5.25,0.25,0.25)$ & $(0.75,1.25,0.25,0.25)$ \\
\hline \multirow[t]{4}{*}{$c_{3}$} & $y_{1}(1), y_{2}(1)$ & $(3.8,4.2,0.2,0.2)$ & $(1.8,2.2,0.2,0.2)$ \\
\hline & $y_{1}(2), y_{2}(1)$ & $(1.8,2.2,0.2,0.2)$ & $(0.8,1.2,0.2,0.2)$ \\
\hline & $y_{1}(1), y_{2}(2)$ & $(0.8,1.2,0.2,0.2)$ & $(0.8,1.2,0.2,0.2)$ \\
\hline & $y_{1}(2), y_{2}(2)$ & $(2.8,3.2,0.2,0.2)$ & $(3.8,4.2,0.2,0.2)$ \\
\hline \multirow[t]{4}{*}{$c_{4}$} & $y_{1}(1), y_{2}(1)$ & $(2.75,3.25,0.25,0.25)$ & $(2.75,3.25,0.25,0.25)$ \\
\hline & $y_{1}(2), y_{2}(1)$ & $(1.75,2.25,0.25,0.25)$ & $(2.75,3.25,0.25,0.25)$ \\
\hline & $y_{1}(1), y_{2}(2)$ & $(1.75,2.25,0.25,0.25)$ & $(4.75,5.25,0.25,0.25)$ \\
\hline & $y_{1}(2), y_{2}(2)$ & $(2.75,3.25,0.25,0.25)$ & $(0.75,1.25,0.25,0.25)$ \\
\hline \multirow[t]{4}{*}{$c_{5}$} & $y_{1}(1), y_{2}(1)$ & $(4.8,5.2,0.2,0.2)$ & $(0.8,1.2,0.2,0.2)$ \\
\hline & $y_{1}(2), y_{2}(1)$ & $(0.8,1.2,0.2,0.2)$ & $(1.8,2.2,0.2,0.2)$ \\
\hline & $y_{1}(1), y_{2}(2)$ & $(0.8,1.2,0.2,0.2)$ & $(2.8,3.2,0.2,0.2)$ \\
\hline & $y_{1}(2), y_{2}(2)$ & $(2.8,3.2,0.2,0.2)$ & $(0.8,1.2,0.2,0.2)$ \\
\hline
\end{tabular}

$\operatorname{Max} v_{1}(A)$

Subject to (Strategic Game Model $F_{1}$ ):

$$
\begin{aligned}
& v_{1}(A)-(4.5,5.5,0.5,0.5) p_{1}-(0.5,1.5,0.5,0.5) p_{2} \leq 0 \\
& v_{1}(A)-(2.5,3.5,0.5,0.5) p_{1}-(1.5,2.5,0.5,0.5) p_{2} \leq 0 \\
& v_{1}(A)-(0.5,1.5,0.5,0.5) p_{1}-(1.5,2.5,0.5,0.5) p_{2} \leq 0 \\
& v_{1}(A)-(4.5,5.5,0.5,0.5) p_{1}-(0.5,1.5,0.5,0.5) p_{2} \leq 0 \\
& p_{1}+p_{2}=1 \\
& p_{1}, p_{2} \geq 0, v_{1}(A): \text { Free variable } \\
& \text { and }
\end{aligned}
$$

Table 11. The payoffs matrix of the singleton coalition strategies for negotiator $y_{1}$.

\begin{tabular}{cccc}
\hline & \multirow{2}{*}{$\begin{array}{c}\text { Strategy } \\
\text { Criteria }\end{array}$} & \multicolumn{2}{c}{ The singleton coalition } \\
\cline { 3 - 4 }$c_{1}$ & \multicolumn{2}{c}{$y_{1}(1)$} & \multicolumn{1}{c}{$y_{1}(2)$} \\
\hline & $A(1), y_{2}(1)$ & $(0.5,1.5,0.5,0.5)$ & $(0.5,1.5,0.5,0.5)$ \\
& $A(2), y_{2}(1)$ & $(0.5,1.5,0.5,0.5)$ & $(2.5,3.5,0.5,0.5)$ \\
& $A(1), y_{2}(2)$ & $(0.5,1.5,0.5,0.5)$ & $(3.5,4.5,0.5,0.5)$ \\
$c_{2}$ & $A(2), y_{2}(2)$ & $(2.5,3.5,0.5,0.5)$ & $(0.5,1.5,0.5,0.5)$ \\
& $A(1), y_{2}(1)$ & $(3.75,4.25,0.25,0.25)$ & $(1.75,2.25,0.25,0.25)$ \\
& $A(2), y_{2}(1)$ & $(1.75,2.25,0.25,0.25)$ & $(2.75,3.25,0.25,0.25)$ \\
& $A(1), y_{2}(2)$ & $(1.75,2.25,0.25,0.25)$ & $(2.75,3.25,0.25,0.25)$ \\
$c_{3}$ & $A(2), y_{2}(2)$ & $(2.75,3.25,0.25,0.25)$ & $(0.75,1.25,0.25,0.25)$ \\
& $A(1), y_{2}(1)$ & $(4.8,5.2,0.2,0.2)$ & $(1.8,2.2,0.2,0.2)$ \\
& $A(2), y_{2}(1)$ & $(1.8,2.2,0.2,0.2)$ & $(0.8,1.2,0.2,0.2)$ \\
& $A(1), y_{2}(2)$ & $(0.8,1.2,0.2,0.2)$ & $(2.75,3.25,0.25,0.25)$ \\
$c_{4}$ & $A(2), y_{2}(2)$ & $(0.8,1.2,0.2,0.2)$ & $(3.8,4.2,0.2,0.2)$ \\
& $A(1), y_{2}(1)$ & $(2.75,3.25,0.25,0.25)$ & $(1.75,2.25,0.25,0.25)$ \\
& $A(2), y_{2}(1)$ & $(2.75,3.25,0.25,0.25)$ & $(2.75,3.25,0.25,0.25)$ \\
& $A(1), y_{2}(2)$ & $(1.75,2.25,0.25,0.25)$ & $(2.75,3.25,0.25,0.25)$ \\
$c_{5}$ & $A(2), y_{2}(2)$ & $(4.75,5.25,0.25,0.25)$ & $(0.75,1.25,0.25,0.25)$ \\
& $A(1), y_{2}(1)$ & $(4.8,5.2,0.2,0.2)$ & $(0.8,1.2,0.2,0.2)$ \\
& $A(2), y_{2}(1)$ & $(0.8,1.2,0.2,0.2)$ & $(1.8,2.2,0.2,0.2)$ \\
& $A(1), y_{2}(2)$ & $(0.8,1.2,0.2,0.2)$ & $(2.8,3.2,0.2,0.2)$ \\
& $A(2), y_{2}(2)$ & $(2.8,3.2,0.2,0.2)$ & $(0.8,1.2,0.2,0.2)$ \\
\hline
\end{tabular}

Table 12. The payoffs matrix of the singleton coalition strategies for negotiator $y_{2}$.

\begin{tabular}{llll}
\hline & & \multicolumn{2}{c}{ The singleton coalition } \\
Criteria $\begin{array}{c}\text { Strategy } \\
\text { combinations }\end{array}$ & \multicolumn{1}{c}{$y_{2}(1)$} & $y_{2}(2)$ \\
\cline { 3 - 4 }$c_{1}$ & & & \\
& $A(1), y_{1}(1)$ & $(1.5,2.5,0.5,0.5)$ & $(2.5,3.5,0.5,0.5)$ \\
& $A(2), y_{1}(1)$ & $(1.5,2.5,0.5,0.5)$ & $(4.5,5.5,0.5,0.5)$ \\
& $A(1), y_{1}(2)$ & $(3.5,4.5,0.5,0.5)$ & $(0.5,4.5,0.5,0.5)$ \\
$c_{2}$ & $A(2), y_{1}(2)$ & $(4.5,5.5,0.5,0.5)$ & $(4.5,5.5,0.5,0.5)$ \\
& $A(1), y_{1}(1)$ & $(2.75,3.25,0.25,0.25)$ & $(1.75,2.25,0.25,0.25)$ \\
& $A(2), y_{1}(1)$ & $(2.75,3.25,0.25,0.25)$ & $(3.75,4.25,0.25,0.25)$ \\
& $A(1), y_{1}(2)$ & $(3.75,4.25,0.25,0.25)$ & $(0.75,1.25,0.25,0.25)$ \\
$c_{3}$ & $A(2), y_{1}(2)$ & $(3.75,4.25,0.25,0.25)$ & $(4.75,5.25,0.25,0.25)$ \\
& $A(1), y_{1}(1)$ & $(0.8,1.2,0.2,0.2)$ & $(0.8,1.2,0.2,0.2)$ \\
& $A(2), y_{1}(1)$ & $(1.8,2.2,0.2,0.2)$ & $(3.8,4.2,0.2,0.2)$ \\
& $A(1), y_{1}(2)$ & $(1.8,2.2,0.2,0.2)$ & $(1.8,2.2,0.2,0.2)$ \\
$c_{4}$ & $A(2), y_{1}(2)$ & $(3.8,4.2,0.2,0.2)$ & $(3.8,4.2,0.2,0.2)$ \\
& $A(1), y_{1}(1)$ & $(2.75,3.25,0.25,0.25)$ & $(3.75,4.25,0.25,0.25)$ \\
& $A(2), y_{1}(1)$ & $(2.75,3.25,0.25,0.25)$ & $(3.75,4.25,0.25,0.25)$ \\
& $A(1), y_{1}(2)$ & $(1.75,2.25,0.25,0.25)$ & $(0.75,1.25,0.25,0.25)$ \\
& $A(2), y_{1}(2)$ & $(3.75,4.25,0.25,0.25)$ & $(0.75,1.25,0.25,0.25)$ \\
$c_{5}$ & $A(1), y_{1}(1)$ & $(0.8,1.2,0.2,0.2)$ & $(2.8,3.2,0.2,0.2)$ \\
& $A(2), y_{1}(1)$ & $(0.8,1.2,0.2,0.2)$ & $(4.8,5.2,0.2,0.2)$ \\
& $A(1), y_{1}(2)$ & $(2.8,3.2,0.2,0.2)$ & $(0.8,1.2,0.2,0.2)$ \\
& $A(2), y_{1}(2)$ & $(3.8,4.2,0.2,0.2)$ & $(0.8,1.2,0.2,0.2)$ \\
\hline & & & \\
& & &
\end{tabular}


Table 13. The payoffs matrix of the coalition strategies between Appllet and negotiator $y_{1}$.

\begin{tabular}{|c|c|c|c|c|c|}
\hline \multirow[b]{2}{*}{ Criteria } & \multirow{2}{*}{$\begin{array}{c}\text { Strategy } \\
\text { combinations }\end{array}$} & \multicolumn{4}{|c|}{ The coalition strategies between $A$ and $y_{1}$} \\
\hline & & $A(1), y_{1}(1)$ & $A(2), y_{1}(1)$ & $A(1), y_{1}(2)$ & $A(2), y_{1}(2)$ \\
\hline \multirow[t]{2}{*}{$c_{1}$} & $y_{2}(1)$ & $(5,7,1,1)$ & $(1,3,1,1)$ & $(3,5,1,1)$ & $(4,6,1,1)$ \\
\hline & $y_{2}(2)$ & $(1,3,1,1)$ & $(4,6,1,1)$ & $(8,10,1,1)$ & $(1,3,1,1)$ \\
\hline \multirow[t]{2}{*}{$c_{2}$} & $y_{2}(1)$ & $(4.5,5.5,0.5,0.5)$ & $(3.5,4.5,0.5,0.5)$ & $(3.5,4.5,0.5,0.5)$ & $(6.5,7.5,0.5,0.5)$ \\
\hline & $y_{2}(2)$ & $(3.5,4.5,0.5,0.5)$ & $(5.5,6.5,0.5,0.5)$ & $(7.5,8.5,0.5,0.5)$ & $(1.5,2.5,0.5,0.5)$ \\
\hline \multirow[t]{2}{*}{$c_{3}$} & $y_{2}(1)$ & $(4.6,5.4,0.4,0.4)$ & $(2.6,3.4,0.4,0.4)$ & $(2.6,3.4,0.4,0.4)$ & $(1.6,2.4,0.4,0.4)$ \\
\hline & $y_{2}(2)$ & $(1.6,2.4,0.4,0.4)$ & $(3.6,4.4,0.4,0.4)$ & $(6.6,7.4,0.4,0.4)$ & $(4.6,5.4,0.4,0.4)$ \\
\hline \multirow[t]{2}{*}{$c_{4}$} & $y_{2}(1)$ & $(3.5,4.5,0.5,0.5)$ & (3. $5,4.5,0.5,0.5)$ & (2. $5,3.5,0.5,0.5)$ & $(5.5,6.5,0.5,0.5)$ \\
\hline & $y_{2}(2)$ & $(3.5,4.5,0.5,0.5)$ & $(7.5,8.5,0.5,0.5)$ & $(5.5,6.5,0.5,0.5)$ & $(1.5,2.5,0.5,0.5)$ \\
\hline \multirow[t]{2}{*}{$c_{5}$} & $y_{2}(1)$ & $(5.6,6.4,0.4,0.4)$ & $(1.6,2.4,0.4,0.4)$ & $(2.6,3.4,0.4,0.4)$ & $(3.6,4.4,0.4,0.4)$ \\
\hline & $y_{2}(2)$ & $(3.6,4.4,0.4,0.4)$ & $(5.6,6.4,0.4,0.4)$ & $(5.6,6.4,0.4,0.4)$ & $(3.6,4.4,0.4,0.4)$ \\
\hline
\end{tabular}

Table 14. The payoffs matrix of the coalition strategies between Appllet and negotiator $y_{2}$.

\begin{tabular}{|c|c|c|c|c|c|}
\hline \multirow[b]{2}{*}{ Criteria } & \multirow{2}{*}{$\begin{array}{c}\text { Strategy } \\
\text { combinations }\end{array}$} & \multicolumn{4}{|c|}{ The coalition strategies between $\mathrm{A}$ and $y_{2}$} \\
\hline & & $A(1), y_{2}(1)$ & $A(2), y_{2}(1)$ & $A(1), y_{2}(2)$ & $A(2), y_{2}(2)$ \\
\hline \multirow[t]{2}{*}{$c_{1}$} & $y_{1}(1)$ & $(6,8,1,1)$ & $(2,4,1,1)$ & $(3,5,1,1)$ & $(6,8,1,1)$ \\
\hline & $y_{1}(2)$ & $(6,8,1,1)$ & $(6,8,1,1)$ & $(5,7,1,1)$ & $(5,7,1,1)$ \\
\hline \multirow[t]{2}{*}{$c_{2}$} & $y_{1}(1)$ & $(6.5,7.5,0.5,0.5)$ & $(4.5,5.5,0.5,0.5)$ & $(3.5,4.5,0.5,0.5)$ & $(6.5,7.5,0.5,0.5)$ \\
\hline & $y_{1}(2)$ & $(4.5,5.5,0.5,0.5)$ & $(6.5,7.5,0.5,0.5)$ & $(5.5,6.5,0.5,0.5)$ & $(5.5,6.5,0.5,0.5)$ \\
\hline \multirow[t]{2}{*}{$c_{3}$} & $y_{1}(1)$ & $(4.6,5.4,0.4,0.4)$ & $(3.6,4.4,0.4,0.4)$ & $(1.6,2.4,0.4,0.4)$ & $(4.6,5.4,0.4,0.4)$ \\
\hline & $y_{1}(2)$ & $(3.6,4.4,0.4,0.4)$ & $(4.6,5.4,0.4,0.4)$ & $(4.6,5.4,0.4,0.4)$ & $(7.6,8.4,0.4,0.4)$ \\
\hline \multirow[t]{2}{*}{$c_{4}$} & $y_{1}(1)$ & $(3.5,4.5,0.5,0.5)$ & $(5.5,6.5,0.5,0.5)$ & $(4.5,5.5,0.5,0.5)$ & $(8.5,9.5,0.5,0.5)$ \\
\hline & $y_{1}(2)$ & $(4.5,5.5,0.5,0.5)$ & $(6.5,7.5,0.5,0.5)$ & $(3.5,4.5,0.5,0.5)$ & $(1.5,2.5,0.5,0.5)$ \\
\hline \multirow[t]{2}{*}{$c_{5}$} & $y_{1}(1)$ & $(5.6,6.4,0.4,0.4)$ & $(1.6,2.4,0.4,0.4)$ & $(4.6,5.4,0.4,0.4)$ & $(7.6,8.4,0.4,0.4)$ \\
\hline & $y_{1}(2)$ & $(3.6,4.4,0.4,0.4)$ & $(4.6,5.4,0.4,0.4)$ & $(3.6,4.4,0.4,0.4)$ & $(1.6,2.4,0.4,0.4)$ \\
\hline
\end{tabular}

Table 15. The payoffs matrix of the coalition strategies between negotiator $y_{1}$ and negotiator $y_{2}$.

\begin{tabular}{|c|c|c|c|c|c|}
\hline \multirow[b]{2}{*}{ Criteria } & \multirow{2}{*}{$\begin{array}{c}\text { Strategy } \\
\text { combinations }\end{array}$} & \multicolumn{4}{|c|}{ The coalition strategies between $y_{1}$ and $y_{2}$} \\
\hline & & $y_{1}(1), y_{2}(1)$ & $y_{1}(2), y_{2}(1)$ & $y_{1}(1), y_{2}(2)$ & $y_{1}(2), y_{2}(2)$ \\
\hline \multirow[t]{2}{*}{$c_{1}$} & $A(1)$ & $(2,4,1,1)$ & $(4,6,1,1)$ & $(3,5,1,1)$ & $(4,6,1,1)$ \\
\hline & $A(2)$ & $(2,4,1,1)$ & $(7,9,1,1)$ & $(7,9,1,1)$ & $(5,7,1,1)$ \\
\hline \multirow[t]{2}{*}{$c_{2}$} & $A(1)$ & $(3.5,4.5,0.5,0.5)$ & $(4.5,5.5,0.5,0.5)$ & $(3.5,4.5,0.5,0.5)$ & $(3.5,4.5,0.5,0.5)$ \\
\hline & $A(2)$ & $(4.5,5.5,0.5,0.5)$ & $(7.5,8.5,0.5,0.5)$ & $(6.5,7.5,0.5,0.5)$ & $(5.5,6.5,0.5,0.5)$ \\
\hline \multirow[t]{2}{*}{$c_{3}$} & $A(1)$ & $(1.6,2.4,0.4,0.4)$ & $(2.6,3.4,0.4,0.4)$ & $(1.6,2.4,0.4,0.4)$ & $(5.6,6.4,0.4,0.4)$ \\
\hline & $A(2)$ & $(2.6,3.4,0.4,0.4)$ & $(4.6,5.4,0.4,0.4)$ & $(5.6,6.4,0.4,0.4)$ & $(4.6,5.4,0.4,0.4)$ \\
\hline \multirow[t]{2}{*}{$c_{4}$} & $A(1)$ & $(3.5,4.5,0.5,0.5)$ & $(3.5,4.5,0.5,0.5)$ & $(4.5,5.5,0.5,0.5)$ & $(3.5,4.5,0.5,0.5)$ \\
\hline & $A(2)$ & $(3.5,4.5,0.5,0.5)$ & $(6.5,7.5,0.5,0.5)$ & $(6.5,7.5,0.5,0.5)$ & $(1.5,2.5,0.5,0.5)$ \\
\hline \multirow[t]{2}{*}{$c_{5}$} & $A(1)$ & $(1.6,2.4,0.4,0.4)$ & $(4.6,5.4,0.4,0.4)$ & $(4.6,5.4,0.4,0.4)$ & $(3.6,4.4,0.4,0.4)$ \\
\hline & $A(2)$ & $(1.6,2.4,0.4,0.4)$ & $(5.6,6.4,0.4,0.4)$ & $(7.6,8.4,0.4,0.4)$ & $(3.6,4.4,0.4,0.4)$ \\
\hline
\end{tabular}

\section{$\operatorname{Max} v_{1}\left(y_{1}\right)$}

Subject to (Strategic Game Model $F_{2}$ ):

$$
\begin{aligned}
& v_{1}\left(y_{1}\right)-(0.5,1.5,0.5,0.5) p_{1}-(0.5,1.5,0.5,0.5) p_{2} \leq 0 \\
& v_{1}\left(y_{1}\right)-(0.5,1.5,0.5,0.5) p_{1}-(2.5,3.5,0.5,0.5) p_{2} \leq 0 \\
& v_{1}\left(y_{1}\right)-(0.5,1.5,0.5,0.5) p_{1}-(3.5,4.5,0.5,0.5) p_{2} \leq 0 \\
& v_{1}\left(y_{1}\right)-(2.5,3.5,0.5,0.5) p_{1}-(0.5,1.5,0.5,0.5) p_{2} \leq 0 \\
& p_{1}+p_{2}=1
\end{aligned}
$$$$
p_{1}, p_{2} \geq 0, v_{1}\left(y_{1}\right): \text { Free variable }
$$$$
\text { and }
$$

$\operatorname{Max} v_{1}\left(y_{2}\right)$

Subject to (Strategic Game Model $F_{3}$ ):

$$
\begin{aligned}
& v_{1}\left(y_{2}\right)-(1.5,2.5,0.5,0.5) p_{1}-(2.5,3.5,0.5,0.5) p_{2} \leq 0 \\
& v_{1}\left(y_{2}\right)-(1.5,2.5,0.5,0.5) p_{1}-(2.5,3.5,0.5,0.5) p_{2} \leq 0 \\
& v_{1}\left(y_{2}\right)-(3.5,4.5,0.5,0.5) p_{1}-(0.5,1.5,0.5,0.5) p_{2} \leq 0 \\
& v_{1}\left(y_{2}\right)-(4.5,5.5,0.5,0.5) p_{1}-(4.5,5.5,0.5,0.5) p_{2} \leq 0 \\
& p_{1}+p_{2}=1
\end{aligned}
$$$$
p_{1}, p_{2} \geq 0, v_{1}\left(y_{2}\right): \text { Free variable }
$$

and 


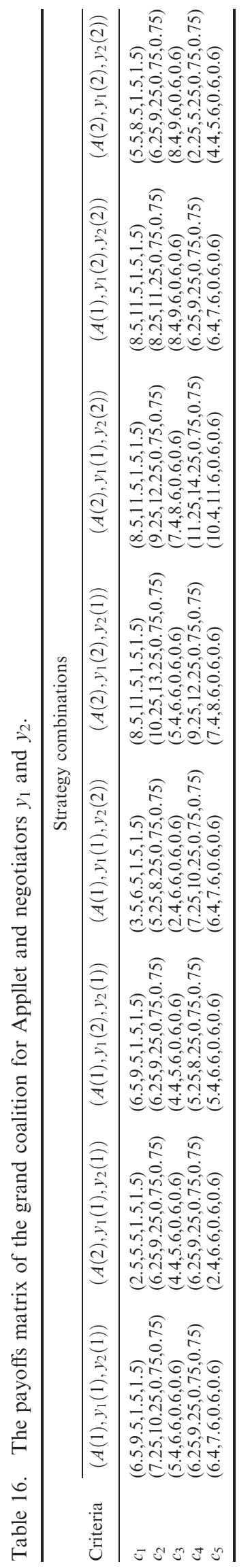

$\operatorname{Max} v_{1}\left(A, y_{1}\right)$

Subject to (Strategic Game Model $F_{4}$ ):

$$
\begin{aligned}
& v_{1}\left(A, y_{1}\right)-(5,7,1,1) p_{1}-(1,3,1,1) p_{2}-(3,5,1,1) p_{3} \\
& \quad-(4,6,1,1) p_{4} \leq 0 \\
& v_{1}\left(A, y_{1}\right)-(1,3,1,1) p_{1}-(4,6,1,1) p_{2}-(8,10,1,1) p_{3} \\
& \quad-(1,3,1,1) p_{4} \leq 0 \\
& p_{1}+p_{2}+p_{3}+p_{4}=1 \\
& p_{1}, p_{2}, p_{3}, p_{4} \geq 0, v_{1}\left(A, y_{1}\right): \text { Free variable }
\end{aligned}
$$

and

$$
\operatorname{Max} v_{1}\left(A, y_{2}\right)
$$

Subject to (Strategic Game Model $F_{5}$ ):

$$
\begin{aligned}
& v_{1}\left(A, y_{2}\right)-(6,8,1,1) p_{1}-(2,4,1,1) p_{2}-(3,5,1,1) p_{3} \\
& \quad-(6,8,1,1) p_{4} \leq 0 \\
& v_{1}\left(A, y_{2}\right)-(6,8,1,1) p_{1}-(6,8,1,1) p_{2}-(5,7,1,1) p_{3} \\
& \quad-(5,7,1,1) p_{4} \leq 0 \\
& p_{1}+p_{2}+p_{3}+p_{4}=1 \\
& p_{1}, p_{2}, p_{3}, p_{4} \geq 0, v_{1}\left(A, y_{2}\right): \text { Free variable }
\end{aligned}
$$

and

$\operatorname{Max} v_{1}\left(y_{1}, y_{2}\right)$

Subject to (Strategic Game Model $F_{6}$ ):

$$
\begin{aligned}
& \quad v_{1}\left(y_{1}, y_{2}\right)-(2,4,1,1) p_{1}-(4,6,1,1) p_{2}-(3,5,1,1) p_{3} \\
& \quad-(4,6,1,1) p_{4} \leq 0 \\
& v_{1}\left(y_{1}, y_{2}\right)-(2,4,1,1) p_{1}-(7,9,1,1) p_{2}-(7,9,1,1) p_{3} \\
& \quad-(5,7,1,1) p_{4} \leq 0 \\
& p_{1}+p_{2}+p_{3}+p_{4}=1
\end{aligned}
$$$$
p_{1}, p_{2}, p_{3}, p_{4} \geq 0, v_{1}\left(A, y_{2}\right) \text { : Free variable }
$$

and

$\operatorname{Max} v_{1}\left(A, y_{1}, y_{2}\right)$

Subject to (Strategic Game Model $F_{7}$ ):

$$
\begin{aligned}
& v_{1}\left(A, y_{1}, y_{2}\right)-(6.5,9.5,1.5,1.5) p_{1}-(2.5,5.5,1.5,1.5) p_{2} \\
& \quad-(6.5,9.5,1.5,1.5) p_{3} \\
& \quad-(3.5,6.5,1.5,1.5) p_{4}-(8.5,11.5,1.5,1.5) p_{5} \\
& \quad-(8.5,11.5,1.5,1.5) p_{6}-(8.5,11.5,1.5,1.5) p_{7} \\
& \quad-(5.5,8.5,1.5,1.5) p_{8} \leq 0 \\
& p_{1}+p_{2}+p_{3}+p_{4}+p_{5}+p_{6}+p_{7}+p_{8}=1 \\
& p_{1}, p_{2}, p_{3}, p_{4}, p_{5}, p_{6}, p_{7}, p_{8} \geq 0, v_{1}\left(A, y_{1}, y_{2}\right): \text { Free variable }
\end{aligned}
$$

Using the Lindo software, the optimal solutions for these models were the values of the characteristic functions as shown in Table 17.

In step 5-3, using Equation (10), the normalised values of the characteristic function was calculated for all coalitions as shown in Table 18. 
Table 17. The values of the characteristic functions for Appllet and negotiators $y_{1}$ and $y_{2}$.

\begin{tabular}{lllll}
\hline Criteria & \multicolumn{1}{c}{ Coalitions } & \multicolumn{2}{c}{ The values of the characteristic functions } \\
\hline$c_{1}$ & Singleton coalitions & $v_{1}(A)=1.8$ & $v_{1}\left(y_{1}\right)=1$ & $v_{1}\left(y_{2}\right)=3$ \\
& 2-coalitions & $v_{1}\left(A, y_{1}\right)=5.11$ & $v_{1}\left(y_{1}, y_{2}\right)=5$ & - \\
$c_{2}$ & Grand coalition & $v_{1}\left(A, y_{1}, y_{2}\right)=10$ & - & $v_{2}\left(y_{2}\right)=3$ \\
& Singleton coalitions & $v_{2}(A)=2.6$ & $v_{2}\left(y_{1}\right)=2.33$ & $v_{2}\left(y_{1}, y_{2}\right)=5$ \\
& 2-coalitions & $v_{2}\left(A, y_{1}\right)=5.33$ & $v_{2}\left(A, y_{2}\right)=6.33$ & - \\
$c_{3}$ & Grand coalition & $v_{2}\left(A, y_{1}, y_{2}\right)=12$ & - & $v_{3}\left(y_{2}\right)=1$ \\
& Singleton coalitions & $v_{3}(A)=1$ & $v_{3}\left(y_{1}\right)=1.67$ & - \\
$c_{4}$ & 2-coalitions & $v_{3}\left(A, y_{1}\right)=4.14$ & $v_{3}\left(A, y_{2}\right)=5$ & $v_{4}\left(y_{2}\right)=2$ \\
& Grand coalition & $v_{3}\left(A, y_{1}, y_{2}\right)=16$ & - & $v_{4}\left(y_{1}, y_{2}\right)=5$ \\
& Singleton coalitions & $v_{4}(A)=1$ & $v_{4}\left(y_{1}\right)=2.5$ & - \\
$c_{5}$ & 2-coalitions & $v_{4}\left(A, y_{1}\right)=5$ & $v_{4}\left(A, y_{2}\right)=6.37$ & $v_{5}\left(y_{2}\right)=2$ \\
& Grand coalition & $v_{4}\left(A, y_{1}, y_{2}\right)=13$ & $v_{5}\left(y_{1}\right)=1.67$ & $v_{5}\left(y_{1}, y_{2}\right)=5$ \\
& Singleton coalitions & $v_{5}(A)=1.67$ & $v_{5}\left(A, y_{2}\right)=4.4$ & - \\
\hline
\end{tabular}

Table 18. The normalised values of the characteristic functions for Appllet and negotiators $y_{1}$ and $y_{1}$.

\begin{tabular}{lllll}
\hline Criteria & \multicolumn{1}{c}{ Coalitions } & \multicolumn{2}{c}{ The normalised values of the characteristic functions } \\
\hline$c_{1}$ & Singleton coalitions & $v_{1}^{\prime}(A)=0$ & $v_{1}^{\prime}\left(y_{1}\right)=0$ & $v_{1}^{\prime}\left(y_{2}\right)=0$ \\
& 2-coalitions & $v_{1}^{\prime}\left(A, y_{1}\right)=.55$ & $v_{1}^{\prime}\left(A, y_{2}\right)=.52$ & - \\
Grand coalition & $v_{1}^{\prime}\left(A, y_{1}, y_{2}\right)=1$ & - & $v_{2}^{\prime}\left(y_{1}, y_{2}\right)=.24$ \\
$c_{2}$ & Singleton coalitions & $v_{2}^{\prime}(A)=0$ & $v_{2}^{\prime}\left(A, y_{2}\right)=.18$ & $v_{2}^{\prime}\left(y_{1}, y_{2}\right)=0$ \\
& 2-coalitions & - & - & - \\
& Grand coalition & $v_{2}^{\prime}\left(A, y_{1}, y_{2}\right)=1$ & $v_{3}^{\prime}\left(y_{1}\right)=0$ & $v_{3}^{\prime}\left(y_{2}\right)=0$ \\
$c_{3}$ & Singleton coalitions & $v_{3}^{\prime}(A)=0$ & $v_{3}^{\prime}\left(A, y_{2}\right)=.24$ & $v_{3}^{\prime}\left(y_{1}, y_{2}\right)=.2$ \\
& 2-coalitions & - & - & $v_{4}^{\prime}\left(y_{2}\right)=0$ \\
$c_{4}$ & Grand coalition & $v_{3}^{\prime}\left(A, y_{1}, y_{2}\right)=1$ & $v_{4}^{\prime}\left(A, y_{2}\right)=.45$ & $v_{4}^{\prime}\left(y_{1}, y_{2}\right)=.07$ \\
& Singleton coalitions & $v_{4}^{\prime}(A)=4$ & - & - \\
& 2-coalitions & $v_{4}^{\prime}\left(A, y_{1}\right)=.2$ & $v_{5}^{\prime}\left(y_{1}\right)=0$ & $v_{5}^{\prime}\left(y_{2}\right)=0$ \\
$c_{5}$ & Grand coalition & $v_{4}^{\prime}\left(A, y_{1}, y_{2}\right)=1$ & $v_{5}^{\prime}\left(A, y_{2}\right)=.13$ & $v_{5}^{\prime}\left(y_{1}, y_{2}\right)=.23$ \\
& Singleton coalitions & $v_{5}^{\prime}(A)=0$ & - & - \\
\hline
\end{tabular}

Next, theses normalised values were used as the right hand side values of the constraints in model $(\mathrm{G})$ to find the Appllet Company's optimal cooperative strategy for the two new products $5 \mathrm{G}_{1}, 5 \mathrm{G}_{2}$ by considering all possible combinations of the two semiconductor companies.

In step 5-4, the imputations and points of the core were determined using the following model $(\mathrm{G})$ :

$\operatorname{Max} \phi$

Subject to (Model G) :

$$
\begin{gathered}
\varphi \leq I(A)+I\left(y_{1}\right)-\operatorname{Min}\left\{v_{1}^{\prime}\left(A, y_{1}\right), v_{2}^{\prime}\left(A, y_{1}\right), v_{3}^{\prime}\left(A, y_{1}\right),\right. \\
\left.v_{4}^{\prime}\left(A, y_{1}\right), v_{5}^{\prime}\left(A, y_{1}\right)\right\} \\
\varphi \leq I(A)+I\left(y_{2}\right)-\operatorname{Min}\left\{v_{1}^{\prime}\left(A, y_{2}\right), v_{2}^{\prime}\left(A, y_{2}\right), v_{3}^{\prime}\left(A, y_{2}\right),\right. \\
\left.v_{4}^{\prime}\left(A, y_{2}\right), v_{5}^{\prime}\left(A, y_{2}\right)\right\} \\
\varphi \leq I\left(y_{1}\right)+I\left(y_{2}\right)-\operatorname{Min}\left\{v_{1}^{\prime}\left(y_{1}, y_{2}\right), v_{2}^{\prime}\left(y_{1}, y_{2}\right), v_{3}^{\prime}\left(y_{1}, y_{2}\right),\right. \\
\left.v_{4}^{\prime}\left(y_{1}, y_{2}\right), v_{5}^{\prime}\left(y_{1}, y_{2}\right)\right\}
\end{gathered}
$$

$I(A)+I\left(y_{1}\right)+I\left(y_{2}\right)=1$

$I(A), I\left(y_{1}\right), I\left(y_{2}\right) \geq 0$

$\phi$ : Free variable

or

\section{$\operatorname{Max} \phi$}

Subject to (Model G) :

$$
\begin{aligned}
& \varphi \leq I(A)+I\left(y_{1}\right)-0.1 \\
& \varphi \leq I(A)+I\left(y_{2}\right)-0.13 \\
& \varphi \leq I\left(y_{1}\right)+I\left(y_{2}\right) \\
& I(A)+I\left(y_{1}\right)+I\left(y_{2}\right)=1 \\
& I(A), I\left(y_{1}\right), I\left(y_{2}\right) \geq 0
\end{aligned}
$$

$\phi$ : Free variable 
The optimal solution for model (G) was: $I^{*}(A)=0.41, I^{*}\left(y_{1}\right)=0.28, I^{*}\left(y_{2}\right)=0.31$ and based on the ranked values $I^{*}\left(y_{1}\right), \ldots, I^{*}\left(y_{n}\right)$, Appllet selected the second negotiator to form the coalition for new product development. Finally, the negotiators reviewed the obtained coalition form and confirmed this joint agreement.

\section{Conclusions and future research directions}

New product development is a complex and collaborative process that requires negotiation and joint decision-making. In principle, each individual treats the new product development problem differently and thus sees it from a distinct perspective. The objective of this study was to integrate a fuzzy cooperative multicriteria game theory and Internet technologies within a collaborative e-negotiation support system for new product development. The study provided a framework for representing multiple viewpoints of a problem, aggregating the preferences of multiple negotiating parties according to various group norms and organising the decision process on the Web.

Future research paths will be fourfold: (1) to explore how similarities and differences among the negotiating interests influence the effectiveness of the enegotiation support process; (2) to explore the effect of different cooperation strategies (i.e. face-to-face versus web-based) on choosing a common strategy to improve the payoffs of the members of the coalition group; (3) to explore the effect of multi-bilateral enegotiations with multiple negotiating parties on the decision-making process because the result of each bilateral negotiation need to be coordinated with those of the other bilateral negotiations; and (4) to explore the role e-negotiations play in organisational longevity because joint agreements that appeared successful in a given problem at first might no longer work out to be effective in the long run.

\section{Acknowledgements}

The authors would like to thank the anonymous reviewers and Dr. Aydin Nassehi, the Managing Editor of the International Journal of Computer Integrated Manufacturing, for their insightful comments and suggestions.

\section{Notes}

1. The name of the company is changed to protect its anonymity.

2. The name of the product is changed to protect its anonymity.

\section{References}

Al-Ahmari, A.M.A., 2008. A methodology for selection and evaluation of advanced manufacturing technologies. International Journal of Computer Integrated Manufacturing, 21 (7), 778-789.
Amaldoss, W., and Rapoport, A., 2005. Collaborative product and market development: theoretical implications and experimental evidence. Marketing Science, 24 (3), 396-414.

Baek, J.G., and Kim, C.O., 2007. Learning single-issue negotiation strategies using hierarchical clustering method. Expert Systems with Applications, 32, 606-615.

Bellman, R., and Zadeh, L.A., 1970. Decision making in a fuzzy environment. Management Science, 17B (4), 141164.

Bui, T., et al., 2001. A multi-attribute negotiation support system with market signaling for electronic markets. Group Decision and Negotiation, 10 (6), 515-537.

Büyüközkan, G., and Arsenyan, J., 2012. Collaborative product development: a literature overview. Production Planning and Control, 23 (1), 47-66.

Büyüközkan, G.G., and Feyzioğlu, O. (2004). A fuzzy-logicbased decision-making approach for new product development. International Journal of Production Economics, 90 (1), 27-45.

Carmel, E., Herniter, B.C., and Nunamaker, J.F., 1993. Labor-management contract negotiation in an electronic meeting room: a case study. Group Decision and Negotiation, 2, 27-60.

Chen, Y.J., 2010. Knowledge integration and sharing for collaborative molding product design and process development. Computers in Industry, 61 (7), 659-675.

Chiang, T.-A., and Che, Z.H., 2010. A fuzzy robust evaluation model for selecting and ranking NPD projects using Bayesian belief network and weight-restricted DEA. Expert Systems with Applications, 37 (11), 74087418.

Chiang, T.-A., and Trappey, A.J.C., 2007. Development of value chain collaborative model for product lifecycle management and its LCD industry adoption. International Journal of Production Economics, 109 (1-2), 90104.

Chiu, D.K.W., et al., 2005. Developing e-negotiation support with a meta-modeling approach in a web services environment. Decision Support Systems, 40, 51-69.

Choy, K.L., et al., 2004. Design of an intelligent supplier relationship management system for new product development. International Journal of Computer Integrated Manufacturing, 17 (8), 692-715.

Cil, I., Alpturk, O., and Yazgan, H.R., 2005. A new collaborative system framework based on a multiple perspective approach: InteliTeam. Decision Support Systems, 39 (4), 619-641.

Davila, T., 2000. An empirical study on the drivers of management control systems' design in new product development. Accounting, Organizations and Society, 25, 383-409.

Espin, R., et al., 2007. A fuzzy approach to cooperative nperson games. European Journal of Operational Research, $176(3), 1735-1751$.

Espinasse, B., Picolet, G., and Chouraqui, E., 1997. Negotiation support systems: a multi-criteria and multiagent approach. European Journal of Operational Research, 103 (2), 389-409.

Fagerström, B., and Jackson, M., 2002. Efficient collaboration between main and sub-suppliers. Computers in Industry, 49 (1), 25-35.

Feyzioğlu, O., and Büyüközkan, G., 2008. An integrated group decision-making approach for new product development. International Journal of Computer Integrated Manufacturing, 21 (4), 366-375. 
Galin, A., Gross, M., and Gosalker, G., 2007. E-negotiation versus face-to-face negotiation what has changed - if anything? Computers in Human Behavior, 23, 787-797.

Hacklin, F., Marxt, C., and Fahrni, F., 2006. Strategic venture partner selection for collaborative innovation in production systems: a decision support system-based approach. International Journal of Production Economics, 104 (1), 100-112.

Haque, B., Pawar, K.S., and Barson, R.J., 2000. Analysing organisational issues in concurrent new product development. International Journal of Production Economics, 67 (2), 169-182.

Harmancioglu, N., et al., 2007. Your new product development (NPD) is only as good as your process: an exploratory analysis of new NPD process design and implementation. R\&D Management, 37 (5), 399-424.

$\mathrm{Hu}$, Y., Zhou, X., and Li, C., 2010. Internet-based intelligent service-oriented system architecture for collaborative product development. International Journal of Computer Integrated Manufacturing, 23 (2), 113-125.

Huang, G.Q., Huang, J., and Mak, K.L., 2000. Agent-based workflow management in collaborative product development on the Internet. Computer-Aided Design, 32 (2), 133-144.

Huang, G.Q., and Mak, K.L., 2002. Agent-based collaboration between distributed Web applications: case study on collaborative design for $\mathrm{X}$, using CyberCO. Concurrent Engineering: Research and Applications, 10 (4), 279-290.

Hung, H.F., Kao, H.P., and Chu, Y.Y., 2008. An empirical study on knowledge integration, technology innovation and experimental practice. Expert Systems with Applications, 35 (1-2), 177-186.

Hung, H.F., Kao, H.P., and Ku, K.C., 2007. Evaluation of design alternatives in collaborative development and production of modular products. International Journal of Advanced Manufacturing Technology, 33 (11-12), 1065-1076.

Jing, N., and Lu, S.C.Y., 2010. Structure arguments for collaborative negotiation of group decisions in manufacturing systems integration. International Journal of Computer Integrated Manufacturing, 23 (8-9), 720-738.

Kebriaei, H., and Johari Majd, V., 2009. A simultaneous multi-attribute soft-bargaining design for bilateral contracts. Expert Systems with Applications, 36 (3), $4417-$ 4422.

Krishnan, V., and Ulrich, K.T., 2001. Product development decisions: a review of the literature. Management Science, 47 (1), 1-21.

Kumar, M., Vrat, P., and Shankar, R., 2004. A fuzzy goal programming approach for vendor selection problem in a supply chain. Computers and Industrial Engineering, $46(1), 69-85$.

Li, H., et al., 2005. Integration of business processes in Webbased collaborative product development. International Journal of Computer Integrated Manufacturing, 18 (6), 452-462.

Li, W.D., and Qiu, Z.M., 2006. State-of-the-art technologies and methodologies for collaborative product development systems. International Journal of Production Research, 44 (13), 2525-2559.

Mallozzi, L., Scalzo, V., and Tijs, S., 2011. Fuzzy interval cooperative games. Fuzzy Sets and Systems, 165 (1), 98105.

Mares, M., 2000. Fuzzy coalition structures. Fuzzy Sets and Systems, 114, 23-33.
Mares, M., 2001. Fuzzy cooperative games. Heidelberg: Physica-Verlag.

Maruca, R.F., 2000. The electronic negotiator. Harvard Business Review, 78 (1), 16-17.

McCain, R.A., 2008. Cooperative games and cooperative organizations. Journal of Socio-Economics, 37, 21552167.

Mikhailov, L., and Tsvetinov, P., 2004. Evaluation of services using a fuzzy analytic hierarchy process. Applied Soft Computing, 5 (1), 23-33.

Ming, X.G., et al., 2008. Collaborative process planning and manufacturing in product lifecycle management. Computers in Industry, 59 (2-3), 154-166.

Molina, A., Aca, J., and Wright, P., 2005. Global collaborative engineering environment for integrated product development. International Journal of Computer Integrated Manufacturing, 18 (8), 635-651.

Munier, B. R., 1993. Are game-theoretic concepts suitable negotiation support tools - from Nash equilibrium refinements toward a cognitive concept of rationality. Theory and Decision, 34 (3), 235-253.

Nagarajan, M., and Sosic, G., 2008. Game-theoretic analysis of cooperation among supply chain agents: review and extensions. European Journal of Operational Research, 187 (3), 719-745.

Nash, J., 1950a. Equilibrium points in n-person games. Proceedings of National Academy of Science, 36 (1), 4849.

Nash, J., 1950b. The bargaining problem. Econometrica, 18 (2), 155-162.

Nishizaki, I., and Sakawa, M., 2000. Fuzzy cooperative games arising from linear production programming problems with fuzzy parameters. Fuzzy Sets and Systems, 114 (1), 11-21.

Noori, H., and Lee, W.B., 2004. Collaborative design in a networked enterprise: the case of the telecommunications industry. International Journal of Production Research, 42 (15), 3041-3054.

Qian, F., and Shenseng, Z., 2002. Product development process management system based on P_PROCE Model. Concurrent Engineering: Research and Applications, 10 (3), 203-211.

Ouzizi, L., et al., 2006. A model for cooperative planning within a virtual enterprise. International Journal of Computer Integrated Manufacturing, 19 (3), 197-209.

Pekec, A., 2001. Meaningful and meaningless solutions for cooperative n-person games. European Journal of Operational Research, 133 (3), 608-623.

Pol, G., et al., 2007. Analysing collaborative practices in design to support project managers. International Journal of Computer Integrated Manufacturing, 20 (7), 654-668.

Porter, M.E., 1980. Competitive strategy: techniques for analyzing industries and competitors. New York: The Free Press.

Renna, P., and Argoneto, P., 2011. Capacity sharing in a network of independent factories: a cooperative game theory approach. Robotics and Computer-Integrated Manufacturing, 27, 405-417.

Rodriguez, K., and Al-Ashaab, A., 2005. Knowledge Webbased system architecture for collaborative product development. Computers in Industry, 56 (1), 125-140.

Schmidt, J. B., Montoya-Weiss, M.M., and Massey, A.P., 2001. New product development decision-making effectiveness: comparing individuals, face-to-face teams, and virtual teams. Decision Sciences, 32 (4), 575-600. 
Shapley, L., 1953. A value for n-person games. In: H.W. Kuhn and A.W. Tucker, eds. Contributions to the theory of games. Princeton, NJ: Princeton University Press, 207317.

Shen, W., Hao, Q., and Li, W., 2008. Computer supported collaborative design: retrospective and perspective. Computers in Industry, 59 (9), 855-862.

Song, D.W., and Panayides, P.M., 2002. A conceptual application of cooperative game theory to linear shipping strategic alliances. Maritime Policy and Management, 29 (3), 285-301.

Thompson, L., 1998. The mind and heart of the negotiator. Upper Saddle River, NJ: Prentice-Hall.

Thompson, L., and Nadler, J., 2002. Negotiating via information technology: theory and application. Journal of Social Studies, 58 (1), 109-124.

Trappey, A.J.C., and Hsiao, D.W., 2008. Applying collaborative design and modularised assembly for automotive ODM supply chain integration. Computers in Industry, 59 (2-3), 277-287.

Tseng, K.C., Abdalla, H., and Shehab, E.M., 2007. A Webbased integrated design system: its applications on conceptual design stage. International Journal of Advanced Manufacturing Technology, 35 (9-10), 10281040.

Tsurumi, M., Tanino, T., and Inuiguchi, M., 2001. A Shapley function on a class of cooperative fuzzy games. European Journal of Operational Research, 129 (3), 596-618.

von Neumann, J., and Morgenstern, D., 1944. The theory of games and economic behavior. New York: Wiley.
Wang, Y.D., Shen, W., and Ghenniwa, H., 2003. WebBlow: a Web/agent-based multidisciplinary design optimization environment. Computers in Industry, 52 (1), 17-28.

Wu, H., 2010. A note on fuzzy coalition structures. Fuzzy Sets and Systems, 161 (20), 2661-2667.

Yan, W., et al., 2006. A study of bidding-oriented collaborative product conceptualization. International Journal of Computer Integrated Manufacturing, 19 (2), 161-177.

Yeh, T.-M., Yang, C.-C., and Pai, F.-Y., 2009. Performance improvement in new product development with effective tools and techniques adoption for high-tech industries. Quality and Quantity, 44 (1), 131-152.

Yoshimura, M., Izui, K., and Kida, S., 2005. Decision support system for selecting collaborative product development partners. Concurrent Engineering: Research and Applications, 13 (1), 5-11.

Zadeh, L.A., 1975. The concept of a linguistic variable and its application to approximate reasoning. Information Sciences, 8, 199-249 (I), 301-357 (II).

Zadeh, L.A., 1965. Fuzzy sets. Information and Control, 8, 338-353.

Zhang, Z., and Chu, X., 2009. A new integrated decisionmaking approach for design alternative selection for supporting complex product development. International Journal of Computer Integrated Manufacturing, 22 (3), 179-198.

Zhao, Y., et al., 2010. Coordination of supply chains by option contracts: a cooperative game theory approach. European Journal of Operational Research, 207, 668-675. 